\title{
Compressive Behavior of Carbon Nanotube Reinforced Polypropylene Composites Under High Strain Rate: Insights From Molecular Dynamics
}

\section{Brijesh Mishra}

Dr BR Ambedkar National Institute of Technology

Sumit Sharma ( $\nabla$ sharmas@nitj.ac.in )

Dr BR Ambedkar National Institute of Technology https://orcid.org/0000-0002-8916-6036

\section{Research Article}

Keywords: Single-walled carbon nanotube, Polypropylene, Defects, Strain rate, Molecular dynamics, Young's modulus

Posted Date: September 20th, 2021

DOI: https://doi.org/10.21203/rs.3.rs-890632/v1

License: (c) (i) This work is licensed under a Creative Commons Attribution 4.0 International License. Read Full License 


\section{Abstract}

Since the discovery of carbon nanotubes (CNTs), these have received a lot of attention because of their unusual mechanical electrical properties. Strain rate is one of the key factors that play a vital role in enhancing the mechanical properties of nanocomposites. In this study, $(4,4)$ armchair single-walled carbon nanotube (SWCNT) was employed with the polymer matrix as polypropylene (PP). The influence of compressive strain rate on SWCNT/PP nanocomposites was evaluated using MD simulations, and mechanical properties have been predicted. Stone-Wales (SW) and vacancy defects, were integrated on the SWCNT. The maximum Young's modulus $(E)$ of $81.501 \mathrm{GPa}$ was found for the pristine SWCNT/PP composite for a strain rate of $10^{10} \mathrm{~s}^{-1}$. The least value of $E$ was $45.073 \mathrm{GPa}$ for $6 \% \mathrm{SW}$ defective/PP composite for a strain rate of $10^{8} \mathrm{~s}^{-1}$. While the $6 \%$ vacancy defective CNT/PP composite showed the lowest value of $E$ as $39.57 \mathrm{GPa}$ for strain rate $10^{8} \mathrm{~s}^{-1}$. It was found that the mechanical properties of SWCNT/PP nanocomposites decrease with the increase in percent defect. It was also seen that the mechanical properties were enhanced with the increment in the applied strain rate. The results obtained from this study could be useful for the researchers designing PP-based materials for compression loading to be used for biomedical applications.

\section{Introduction}

Carbon nanotubes commonly known as CNT, have outstanding properties and an extensive collection of applications. That is why these have gathered considerable attention recently. Researchers across the world have worked tirelessly over the last decade to produce CNT fiber, which has emerged as a distinct novel part of the carbon fiber family unit. The study of CNT both experimentally and theoretically has increased extensively because of its exceptional mixture of electrical, mechanical, thermal, chemical properties [1]. Synergistic improvement in composite characteristics at small volume fractions is due to the inclusion of CNT in polymer matrices. Many studies and researches have been done regarding the mechanical properties of the interface between CNT and matrix. Because of the outstanding properties of CNTs, these are planned to be used as field-effect transistor (FET) materials, nanoscale wire materials, electron emission sources, chemical sensors, optical communication switches, high strength composites, and thermal devices. CNTs acquire high tensile modulus and strength. Strong composites can be designed and fabricated by using the CNTs as reinforcing filler and thus can be used to develop and produce strong composites. The mechanical strength of the composites can decrease due to defective CNTs. Some of the defects are Stone-Wales (SW) and vacancy defects. The outcome of the mechanical properties is important to analyze when any of the parameters are mean to vary. On varying the input values of parameters, the mechanical properties of SWCNT-PP nanocomposites can be affected considerably. This study will be focused on analyzing this impact. Many researchers have been interested in the influence of strain rates on the mechanical behavior of several nanocomposites in recent years. It was found that strain rate has enhanced the mechanical properties. Thus strain rate is one of the key factors that play a vital role to enhance the mechanical property of nanocomposites. In past studies, the 
SWCNT/PP nanocomposites have not been investigated by varying the strain rate. In this study, the influence of compressive strain rate on SWCNT/PP nanocomposites has been examined.

Parvaneh and Shariati [2] examined the influence of SW defects and vacancy defects on Young's modulus of SWCNT. A structural mechanics model was constructed to investigate Young's modulus. The tension test was reported as the best method for measuring Young's modulus of CNT. It was concluded that when CNTs are sufficiently large, imperfections have a negligible effect. Jacob et al. [3] reviewed the impact of strain rate on the mechanical properties. It was observed that many researchers have looked into the effect of variable loading rate on the tensile, compressive, shear, and flexural properties of fiberreinforced nanocomposites, with a range of conflicting explanations and conclusions. Saxena and Lal [4] investigated the effects on the mechanical properties of SWCNT produced by SW defects and vacancy defects. The vacancy and SW defects ranged from 1 to 4 and their relative positions and orientations were varied. The investigation reported that vacancy defects have reduced the tensile strength and strain more than the SW defects. Yang et al. [5] studied the effect of SW defect on the characteristics of SWCNT/PP composites using the molecular dynamics (MD) simulation technique. A $(15,0)$ zigzag CNT with several defects i.e. 0,5, 10, 15 were studied. The strain rate was put as $0.0001 / p s$. The outer strain was amplified up to $2 \%$ in all defects cases. It was seen that Young's modulus of SWCNTs decreased when the number of SW defects rises. As the number of SW defects increases, the interfacial bonding becomes stronger, improving the transverse Young's modulus and two shear moduli.

Sharma et al. [6] investigated the consequence of SW and vacancy defects on Young's modulus of CNTs and their nanocomposites. The impact of varying the diameter of faulty SWCNTs on their Young's modulus was also investigated using MD modeling. The study showed that as the diameter and the number of defects in armchair SWCNT were increased, the elastic moduli were gradually degraded. The moduli of SWCNTs having SW defects declined at a faster rate than the moduli of CNTs with vacancy defects as the number of defects was increased. It was deduced that the presence of SW or vacancy defects in an SWCNT system degrades the mechanical characteristics of the structure. It was also found that in contrast to SWCNTs with SW defects, the percentage rise in different moduli with increasing volume fraction $\left(V_{f}\right)$ was larger for SWCNTs having vacancy flaws. Li et al. [7] examined the results of temperature, strain rate, and molecule length on the deformation of graphene/polyethylene composites. It was seen that the host molecules migrated more easily at higher temperatures to suit the strain during deformation. It was observed that the nanocomposite model's atoms were more stress-free to meet the strain when the strain rate was lower.

Zhang et al. [8] investigated the impact of strain rate and temperature on the interfacial property of glass fiber reinforced PP nanocomposites by MD simulation. Since at higher strain rates atoms do not have enough time, interfacial strength was improved as the strain rate was increased. It was found that with the increase of strain rate the yield stress and elastic modulus were increased. The study suggested that the atoms were less stress-free at greater strain rates, requiring more fracture energies for the ultimate fracture, resulting in higher interfacial strength at the glass fiber-PP interface. Khan et al. [9] used functionalized MWCNTs and hydroxyapatite nano-rods reinforced with PP for bio-medical applications. 
Schossig et al. [10] observed the consequence of strain rate on mechanical properties of reinforced polyolefins. High-speed tensile tests were performed on glass-fiber reinforced thermoplastic materials. PP and polybutene- 1 having the weight percentage (\%wt) $0,20,30$, and 40 of glass fiber were used. The results of the tests revealed that the glass fiber reinforced polypropylene (GFRPP) and polybutene-1 (PB1) exhibit a positive strain rate dependent relative nature as well. In contrast to low strain rates, high strain rates resulted in a stronger increase in tensile strength. It was reported that PP materials have superior strength levels than PB-1 materials. Fitoussi et al. [11] examined the influence of the strain rate on the mechanical properties of a discontinuous glass fiber reinforced ethylene-propylene copolymer matrix nanocomposite. A 50 percent increase in Young's modulus with the increase in strain rate was observed. A substantial rise in the damaging stress and strain thresholds was observed.

Notta-Cuvier et al. [12] studied the influence of strain rate and heterogeneous fiber orientation on the mechanical behavior of short-glass fiber reinforced PP. The composite's tensile macroscopic behavior was investigated in a quasi-static and dynamic range from $1 \mathrm{~mm} / \mathrm{min}$ to $1 \mathrm{~m} / \mathrm{s}$ at various angles of loading concerning the injection flow direction and variable displacement rates. It was observed that tensile strength and stiffness increased with the increment in strain rate. Cui et al. [13] studied the impact of strain rates on mechanical characteristics and failure behavior of long glass fiber reinforced (LGFR) thermoplastic composites. At high strain rates, the increase in ultimate strength and breakage strain of LGFR-PPs was due to improvements in interfacial bonding characteristics and energy amalgamation capacity. Kim et al. [14] investigated the strain rate-dependent mechanical behavior of glass fiber reinforced polypropylene nanocomposites. Zhang et al. [15] investigated the impact of strain rate and temperature on the interfacial property of glass fiber reinforced PP nanocomposites by MD simulation. It was reported that the interfacial strength of the glass fiber-PP interface reduced when PP molecules shifted more easily to adjust tensile strain.

From the literature, it could be seen that inadequate work has been done to analyze the effect of compressive strain rate on mechanical properties of SWCNT reinforced PP nanocomposites. MD simulation can provide useful atomistic insights into the compressive behavior of SWCNT/PP composites. The effect of SW and vacancy defective CNTs on the mechanical properties of PP composites have also been predicted using MD simulation. The results obtained from this study could be useful for the researchers designing PP based materials for compression loading to be used for biomedical applications.

\section{Methodology}

The following steps explain the procedure used in this work to model and simulate the CNT-PP composites. All the simulations were performed using Biovia Materials Studio 2017. By using the "Build nanostructure" module a $(4,4)$ armchair SWCNT was constructed. Simulations were performed on pristine as well as defective SWCNTs. SW and vacancy defects were integrated into the SWCNTs as shown in Fig. 1 and Fig. 2, respectively. 2\%, 4\%, and 6\% defects were formed for both types of defects. A PP chain was created by using the "Build Polymer" module as shown in Fig. 3. The PP chain was cleaned to 
optimize the bond angles of the chain. A cell was built using the "Build Crystal" option. An isosurface was formed around the SWCNT as shown in Fig. 4. The "Amorphous" module was used to pack the PP chain inside the cell. 18 units of PP were loaded randomly around the SWCNT as shown in Fig. 5. The targeted density was kept at $0.80 \mathrm{~g} / \mathrm{cm}^{3}$. For this process COMPASS (Condensed-phase Optimized Molecular Potentials for Atomistic Simulation Studies) forcefield was selected.

After packing, the geometry optimization was performed. This phase is very important since configurations are in a greater level of energy at the start and it must be reduced. There are several methods available for geometry optimization. In this study, the "smart" algorithm was used as an optimization technique. 'Smart' algorithm uses other optimization techniques such as conjugate gradient, steepest descent, and Newton-Raphson technique. After the geometry optimization, the energy of the structure gets minimized. It is called a converged structure. Now once the energy is minimized, dynamics run can be performed on the structure. In the dynamics run, simulation is performed on the atoms in a structure that move under the impact of calculated forces regulated by an 'ensemble' mathematical device. The canonical ensemble with a constant number of atoms, volume, and temperature (NVT) and isothermal-isobaric ensemble (NPT) were used in this investigation. Nose-Hoover's extended Hamilton method was used to perform NVT with a time step of $1 \mathrm{fs}$ for $50 \mathrm{ps}$. The details of the NVT ensemble simulation have been given in Table 1. NPT ensemble was employed for anisotropic management of the pressure tensor that promotes proficient convergence and command of the unit cell dimension and density. In this process, Nose-Hoover's barostat was used for NPT at 200K and 1 atm for 500ps. NoseHoover's barostat was used because it controls the pressure of the unit cell using the NPT ensemble. The detail of the NPT ensemble simulation has been given in Table 2.

Table 1

NVT ensembles parameters.

\begin{tabular}{|ll|}
\hline Parameter & Input \\
\hline Ensemble & NVT \\
\hline Forcefield & COMPASS \\
\hline Quality & Medium \\
\hline Initial velocities & Random \\
\hline Temperature & $200 \mathrm{~K}$ \\
\hline Time-step & $1 \mathrm{fs}$ \\
\hline Total simulation time & $50 \mathrm{ps}$ \\
\hline Thermostat & $\mathrm{NHL}$ \\
\hline Number of steps & 50000 \\
\hline Energy Deviation & $5 \times 10^{12} \mathrm{kcal} / \mathrm{mol}$ \\
\hline
\end{tabular}


Table 2

NPT ensembles parameters.

\begin{tabular}{|ll|}
\hline Parameter & Input \\
\hline Ensemble & NPT \\
\hline Forcefield & COMPASS \\
\hline Quality & Medium \\
\hline Initial velocities & Random \\
\hline Temperature & $200 \mathrm{~K}$ \\
\hline Pressure & $1 \mathrm{~atm}$ \\
\hline Time-step & $1 \mathrm{fs}$ \\
\hline Total simulation time & $500 \mathrm{ps}$ \\
\hline Thermostat & $\mathrm{NHL}$ \\
\hline Barostat & Berendsen \\
\hline Energy deviation & $5 \times 10^{12} \mathrm{kcal} / \mathrm{mol}$ \\
\hline
\end{tabular}

After the completion of the dynamics run, a strain rate was applied to the system to study its effect on the mechanical behavior of SWCNT/PP nanocomposites. The stress-strain relationship was obtained by varying the strain rate. Once the strain rate simulation was completed, mechanical properties were predicted from the stress-strain curves. The parameters of strain rate have been mentioned in Table 3 .

Table 3

Parameter for strain rates.

\begin{tabular}{|llll|}
\hline Parameter & Input & & \\
\hline Strain Rate & $10^{8} \mathrm{~s}^{-1}$ & $10^{9} \mathrm{~s}^{-1}$ & $10^{10} \mathrm{~s}^{-1}$ \\
\hline Module & Forcite & Forcite & Forcite \\
\hline Forcefield & COMPASS & COMPASS & COMPASS \\
\hline Number strains & 100 & 100 & 100 \\
\hline Compression factor & 0.002 & 0.002 & 0.002 \\
\hline Number steps & 20000 & 20000 & 20000 \\
\hline Timestep & $1 \mathrm{fs}$ & $0.1 \mathrm{fs}$ & $0.01 \mathrm{fs}$ \\
\hline
\end{tabular}

\section{Results And Discussion}




\subsection{Pristine SWCNT/PP nanocomposite}

The stress-strain curves of $(4,4)$ SWCNT/PP nanocomposite for strain rates of $10^{8} \mathrm{~s}^{-1}, 10^{9} \mathrm{~s}^{-1}$, and $10^{10}$ $\mathrm{s}^{-1}$ have been shown in Fig. 6. Figure 6 indicated a linear variation up to stress of $1.406902 \mathrm{GPa}$, $1.444225 \mathrm{GPa}, 1.793013 \mathrm{GPa}$ at strains of $0.02,0.022,0.022$ for strain rates of $10^{8} \mathrm{~s}^{-1}, 10^{9} \mathrm{~s}^{-1}$, and $10^{9}$ $\mathrm{s}^{-1}$ respectively. The variation in stress for a strain rate of $10^{8} \mathrm{~s}^{-1}$ was $2.65 \%$ and $27.44 \%$ respectively. After this, the yielding occurred. After the yielding, the curve again started rising. After the ultimate stress, the curve again started declining on applying further stress. The Young's moduli of pristine SWCNT/PP were $70.346 \mathrm{GPa}, 72.711 \mathrm{GPa}$, and $81.501 \mathrm{GPa}$ for strain rates of $10^{8} \mathrm{~s}^{-1}, 10^{9} \mathrm{~s}^{-1}$, and $10^{9} \mathrm{~s}^{-1}$ respectively.

\subsection{SW defective SWCNT/PP nanocomposites 3.2.1 Stress-strain behavior for $2 \%$ SW defect}

The stress-strain curve was obtained for $2 \%$ SW defective $(4,4)$ SWCNT/PP nanocomposites. The curve was plotted for various strain rates of $10^{8} \mathrm{~s}^{-1}, 10^{9} \mathrm{~s}^{-1}$, and $10^{9} \mathrm{~s}^{-1}$ as shown in Fig. 7. For a strain rate of $10^{8} \mathrm{~s}^{-1}$, the linear behavior was up to the stress of $1.369206 \mathrm{GPa}$ at a strain of 0.022 . The variation in the stress was $4.67 \%$ for a strain rate of $10^{8} \mathrm{~s}^{-1}$. While for the strain rate of $10^{10} \mathrm{~s}^{-1}$ the variation in the value of stress up to linear behavior was $23.45 \%$ for the strain rate $10^{8} \mathrm{~s}^{-1}$.

\subsubsection{Stress-strain behavior for $4 \% \mathrm{SW}$ defect}

The stress-strain curve of $(4,4) 4 \%$ SW defective SWCNT/PP nanocomposites has been depicted in Fig. 8 for various strain rates. At a strain of 0.02 , the linear variation was detected up to $1.104892 \mathrm{GPa}$ for a strain rate of $10^{8} \mathrm{~s}^{-1}$. For the strain rate of $10^{9} \mathrm{~s}^{-1}$, the linear fluctuation was observed up to stress $1.217986 \mathrm{GPa}$ at a strain of 0.02 as shown in the curve. The variation of the stress for a strain rate of $10^{9}$ $s^{-1}$ was $10.23 \%$ for the strain rate of $10^{8} s^{-1}$. The linear fluctuation was visible in the curve for a strain rate of $10^{10} \mathrm{~s}^{-1}$ up to the stress of $1.569375 \mathrm{GPa}$. At this value, the strain was 0.022 . It was found that stress varied by $42.03 \%$ for a strain rate of $10^{8} \mathrm{~s}^{-1}$.

\subsubsection{Stress-strain behavior for $6 \% \mathrm{SW}$ defect}

In Fig. 9, the stress-strain curve of $(4,4) 6 \%$ SW defective SWCNT/PP nanocomposites for various strain rates has been plotted. The linear variation for the strain rate of $10^{8} \mathrm{~s}^{-1}, 10^{9} \mathrm{~s}^{-1}$, and $10^{10} \mathrm{~s}^{-1}$ was indicated up to the stress of $0.901457 \mathrm{GPa}, 0.943118 \mathrm{GPa}$, and $1.328926 \mathrm{GPa}$ respectively. These stresses were found at a strain of 0.02 . The stress for a strain rate of $10^{9} \mathrm{~s}^{-1}$ had a $4.6 \%$ difference with respect to the strain rate of $10^{8} \mathrm{~s}^{-1}$. While for strain rate of $10^{10} \mathrm{~s}^{-1}$ the value of the stress varied with $47.4 \%$ with respect to strain rate $10^{8} \mathrm{~s}^{-1}$. Yielding was observed at strain 0.02 . Following the yielding, the 
curve began to rise once more. At 0.068 strain, the ultimate stress was achieved for strain rates $10^{8} \mathrm{~s}^{-1}$ and $10^{9} \mathrm{~s}^{-1}$. While for strain rate $10^{10} \mathrm{~s}^{-1}$, ultimate stress was found at 0.078 .

\subsubsection{Variation of Young's modulus for various strain rates with SW defects}

The variation of Young's modulus for $(4,4)$ SW defective SWCNT/PP nanocomposites with a variety of strain rates has been shown in Fig. 10. It could be observed that with the varying strain rate Young's modulus also gets affected as shown in Table 4. As the strain rate increases, Young's modulus of the SWCNT-PP nanocomposites also improved. In this investigation, it was also found that with the increment of the percent SW defects, Young's modulus decreases continuously. This decrement occurred due to the conversion of the C-C polygon chain. In SW defective CNTs, 4 hexagonal C-C chains were converted into two pentagons and two heptagon $\mathrm{C}-\mathrm{C}$ chains. The maximum Young's modulus was found for the strain rate of $10^{10} \mathrm{~s}^{-1}$.

Table 4

Comparison of Young's modulus for SW defective SWCNT/PP nanocomposites with various strain rates.

\begin{tabular}{|c|c|c|c|c|c|}
\hline \multirow{2}{*}{$\begin{array}{l}\text { Types of } \\
\text { SWCNT }\end{array}$} & \multirow{2}{*}{$\begin{array}{l}\text { Strain } \\
\text { Rate } 10^{8} \\
\mathrm{~s}^{-1} \\
\text { Young's } \\
\text { Modulus } \\
(\mathrm{GPa})\end{array}$} & \multicolumn{2}{|c|}{ Strain Rate $10^{9} \mathrm{~s}^{-1}$} & \multicolumn{2}{|c|}{ Strain Rate $10^{10} \mathrm{~s}^{-1}$} \\
\hline & & $\begin{array}{l}\text { Young's } \\
\text { Modulus } \\
\text { (GPa) }\end{array}$ & $\begin{array}{l}\text { \% Difference with } \\
\text { Strain Rate } 10^{8} \mathrm{~s}^{-1}\end{array}$ & $\begin{array}{l}\text { Young's } \\
\text { Modulus } \\
\text { (GPa) }\end{array}$ & $\begin{array}{l}\text { \% Difference with } \\
\text { Strain Rate } 10^{8} \mathrm{~s}^{-1}\end{array}$ \\
\hline Pristine & 70.346 & 72.711 & 3.36 & 81.501 & 15.85 \\
\hline $\begin{array}{l}2 \% \text { SW } \\
\text { Defect }\end{array}$ & 62.237 & 65.144 & 4.67 & 76.835 & 23.45 \\
\hline $\begin{array}{l}4 \% \text { SW } \\
\text { Defect }\end{array}$ & 55.245 & 60.899 & 10.23 & 71.335 & 29.12 \\
\hline $\begin{array}{l}6 \% \text { SW } \\
\text { Defect }\end{array}$ & 45.073 & 47.156 & 4.62 & 66.446 & 47.41 \\
\hline
\end{tabular}

\subsubsection{Yield strength for various strain rates with SW defects}

The yield strength for different strain rates of $(4,4)$ SW defective SWCNT/PP nanocomposites has been plotted in Fig. 11. Table 5 shows the comparison of yield strength with strain rate. It was observed that with the increase in strain rate, the yield strength of the SWCNT/PP nanocomposites enhanced. It was also seen throughout this study that when the percent SW defects increase, yield strength falls. In the SW defect, the $\mathrm{C}-\mathrm{C}$ polygon chain was converted, which resulted in this decrease. While the formation of the SW defect in SWCNT, four hexagons C-C chains transformed into the two pentagons and two heptagon C$\mathrm{C}$ chains. In the plot, it could be seen that the strain rate of $10^{10} \mathrm{~s}^{-1}$ had the maximum yield strength. 
Table 5

Comparison of yield strength for SW defective SWCNT/PP nanocomposites with various strain rates.

\begin{tabular}{|c|c|c|c|c|c|}
\hline \multirow{2}{*}{$\begin{array}{l}\text { Types of } \\
\text { SWCNT }\end{array}$} & \multirow{2}{*}{$\begin{array}{l}\text { Strain Rate } \\
10^{8} \mathrm{~s}^{-1} \\
\text { Yield } \\
\text { Strength } \\
(\mathrm{GPa})\end{array}$} & \multicolumn{2}{|c|}{ Strain Rate $10^{9} \mathrm{~s}^{-1}$} & \multicolumn{2}{|c|}{ Strain Rate $10^{10} \mathrm{~s}^{-1}$} \\
\hline & & $\begin{array}{l}\text { Yield } \\
\text { Strength } \\
\text { (GPa) }\end{array}$ & $\begin{array}{l}\text { \% Difference with } \\
\text { Strain Rate } 10^{8} \mathrm{~s}^{-1}\end{array}$ & $\begin{array}{l}\text { Yield } \\
\text { Strength } \\
\text { (GPa) }\end{array}$ & $\begin{array}{l}\text { \% Difference with } \\
\text { Strain Rate } 10^{8} \mathrm{~s}^{-1}\end{array}$ \\
\hline Pristine & 1.4069 & 1.4542 & 3.36 & 1.793 & 27.44 \\
\hline $\begin{array}{l}2 \% \text { SW } \\
\text { Defect }\end{array}$ & 1.3692 & 1.4332 & 4.67 & 1.6904 & 23.45 \\
\hline $\begin{array}{l}4 \% \text { SW } \\
\text { Defect }\end{array}$ & 1.1049 & 1.2179 & 10.22 & 1.5694 & 42.04 \\
\hline $\begin{array}{l}6 \% \text { SW } \\
\text { Defect }\end{array}$ & 0.9015 & 0.9431 & 4.61 & 1.3289 & 47.41 \\
\hline
\end{tabular}

\subsubsection{Compressive strength for various strain rates with SW defects}

The variation of the compressive strength has been shown in Fig. 12 for $(4,4)$ SW defective SWCNT/PP nanocomposites with a variety of strain rates. In this study, it was noted that compressive strength was also impacted by different strain rates. The compressive strength of the SWCNT-PP nanocomposites was enhanced as on increasing the strain rate. The comparison of compressive strength with strain rate has been listed in Table 6. It was found that the value of compressive strength decreases continuously with the increase in the percent SW defects. The conversion of the C-C polygon chain caused this decrease. Due to the SW defects in SWCNT, four hexagon C-C chains were transformed into two pentagons and two heptagon $\mathrm{C}-\mathrm{C}$ chains. It was observed that the maximum compressive strength was achieved for the strain rate of $10^{10} \mathrm{~s}^{-1}$. 
Table 6

Comparison of compressive strength for SW defective SWCNT/PP nanocomposites with various strain rates.

\begin{tabular}{|c|c|c|c|c|c|}
\hline \multirow{2}{*}{$\begin{array}{l}\text { Types } \\
\text { of } \\
\text { SWCNT }\end{array}$} & \multirow{2}{*}{$\begin{array}{l}\text { Strain Rate } \\
10^{8} \mathrm{~s}^{-1} \\
\text { Compressive } \\
\text { Strength } \\
(\mathrm{GPa})\end{array}$} & \multicolumn{2}{|c|}{ Strain Rate $10^{9} \mathrm{~s}^{-1}$} & \multicolumn{2}{|c|}{ Strain Rate $10^{10} \mathrm{~s}^{-1}$} \\
\hline & & $\begin{array}{l}\text { Compressive } \\
\text { Strength } \\
(\mathrm{GPa})\end{array}$ & $\begin{array}{l}\text { \% Difference with } \\
\text { Strain Rate } 10^{8} \mathrm{~s}^{-1}\end{array}$ & $\begin{array}{l}\text { Compressive } \\
\text { Strength } \\
(\mathrm{GPa})\end{array}$ & $\begin{array}{l}\text { \% Difference with } \\
\text { Strain Rate } 10^{8} \\
\mathrm{~s}^{-1}\end{array}$ \\
\hline Pristine & 2.5597 & 2.6646 & 4.09 & 3.0258 & 18.20 \\
\hline $\begin{array}{l}2 \% \text { SW } \\
\text { Defect }\end{array}$ & 2.3902 & 2.4269 & 1.53 & 2.8313 & 23.45 \\
\hline $\begin{array}{l}4 \% \text { SW } \\
\text { Defect }\end{array}$ & 2.2047 & 2.2396 & 1.58 & 2.6736 & 44.11 \\
\hline $\begin{array}{l}6 \% \text { SW } \\
\text { Defect }\end{array}$ & 1.5103 & 1.5524 & 2.78 & 1.9638 & 30.02 \\
\hline
\end{tabular}

\subsection{Vacancy defective SWCNT/PP nanocomposites 3.3.1 Stress-strain curve for $2 \%$ vacancy defects}

The stress-strain curve for various strain rates of $(4,4) 2 \%$ vacancy defective SWCNT/PP nanocomposites has been shown in Fig. 13. For the strain rate of $10^{8} \mathrm{~s}^{-1}$, stress was $1.357994 \mathrm{GPa}$ at a strain of 0.022 . The curve began to rise once more following the yielding. For the strain rate of $10^{8} \mathrm{~s}^{-1}$, the ultimate stress was achieved at 0.052 strain. It was noted that for the strain rate of $10^{9} \mathrm{~s}^{-1}$, the yielding occurred at strain 0.22 with the stress of $1.421964 \mathrm{GPa}$. While the value of stress for a strain rate of $10^{10} \mathrm{~s}^{-1}$ was $1.648634 \mathrm{GPa}$ at strain 0.022 where the yielding took place. The percentage difference in stress for a strain rate of $10^{9} \mathrm{~s}^{-1}$ and $10^{10} \mathrm{~s}^{-1}$ was $4.71 \%$ and $21.4 \%$ respectively. It was seen that the ultimate stress was obtained at a strain of 0.056 and 0.078 for strain rates $10^{9} \mathrm{~s}^{-1}$, and $10^{10} \mathrm{~s}^{-1}$ respectively.

\subsubsection{Stress-strain curve for $4 \%$ vacancy defects}

The stress-strain curve of $(4,4) 4 \%$ vacancy defective SWCNT/PP nanocomposites has been depicted in Fig. 14 for various strain rates. For the strain rate $10^{8} \mathrm{~s}^{-1}$, the linear variation could be detected up to $0.976698 \mathrm{GPa}$. At this point, the yielding occurred having strain 0.02 . For a strain rate of $10^{9} \mathrm{~s}^{-1}$, the linear fluctuation up to the stress of $0.998963 \mathrm{GPa}$ at a strain of 0.02 was observed as shown in the curve. The variation of the stress for a strain rate of $10^{9} \mathrm{~s}^{-1}$ was $2.27 \%$ for the strain rate of $10^{8} \mathrm{~s}^{-1}$. At 0.058 strain, the maximum stress was achieved. The linear fluctuation for a strain rate of $10^{10} \mathrm{~s}^{-1}$ was noted in the stress-strain curve up to the stress of $1.102689 \mathrm{GPa}$. Following the yielding at strain 0.02 , the curve began to rise once more. It was found that stress varied by $12.89 \%$ for strain rate $10^{10} \mathrm{~s}^{-1}$ for a strain rate of $10^{8} \mathrm{~s}^{-1}$. 


\subsubsection{Stress-strain curve for $6 \%$ vacancy defects}

In Fig. 15, the stress-strain curve of $(4,4) 6 \%$ vacancy defective SWCNT/PP nanocomposites for various strain rates has been plotted. The linear variation for the strain rate of $10^{8} \mathrm{~s}^{-1}, 10^{9} \mathrm{~s}^{-1}$, and $10^{10} \mathrm{~s}^{-1}$ was indicated up to the stress of $0.791399 \mathrm{GPa}, 0.831399 \mathrm{GPa}$, and $0.984967 \mathrm{GPa}$ respectively. These stresses were found at a strain of 0.02 . The stress for a strain rate of $10^{9} \mathrm{~s}^{-1}$ had a $5.05 \%$ difference for a strain rate of $10^{8} \mathrm{~s}^{-1}$. While for strain rate of $10^{10} \mathrm{~s}^{-1}$ the value of stress varied by $24.45 \%$ for a strain rate of $10^{8} \mathrm{~s}^{-1}$. Yielding was observed at strain 0.02. After the yielding, the curve started to increase again. At 0.076 strain, the ultimate stress was achieved for strain rates of $10^{8} \mathrm{~s}^{-1}$. For a strain rate of $10^{9} \mathrm{~s}^{-1}$ ultimate stress was achieved at strain 0.078 . While for strain rate of $10^{10} \mathrm{~s}^{-1}$, ultimate stress was found at 0.088 . After the ultimate stress, the curve again started declining on applying further stress. On further compression after the ultimate stress, the curve started to decrease.

\subsubsection{Young's modulus for various strain rates with vacancy defects}

The variation of Young's modulus for a $(4,4)$ vacancy defective SWCNT/PP nanocomposites with a variety of strain rates has been shown in Fig. 16. It could be seen that as the strain rate varies, Young's modulus also gets affected as shown in Table 7. As the strain rate increases, Young's modulus of the SWCNT-PP nanocomposites was also enhanced. In this investigation, it was also found that with the increment of the percent vacancy defects, Young's modulus decreases continuously. This decrement occurred due to the reduction in the carbon atom of SWCNT. The maximum Young's modulus was found for a strain rate of $10^{10} \mathrm{~s}^{-1}$. 
Table 7

Comparison of Young's modulus for vacancy defective SWCNT/PP nanocomposites with various strain rates.

\begin{tabular}{|c|c|c|c|c|c|}
\hline \multirow{2}{*}{$\begin{array}{l}\text { Types of } \\
\text { SWCNT }\end{array}$} & \multirow{2}{*}{$\begin{array}{l}\text { Strain } \\
\text { Rate } 10^{8} \\
\mathrm{~s}^{-1} \\
\text { Young's } \\
\text { Modulus } \\
(\mathrm{GPa})\end{array}$} & \multicolumn{2}{|c|}{ Strain Rate $10^{9} \mathrm{~s}^{-1}$} & \multicolumn{2}{|c|}{ Strain Rate $10^{10} \mathrm{~s}^{-1}$} \\
\hline & & $\begin{array}{l}\text { Young's } \\
\text { Modulus } \\
\text { (GPa) }\end{array}$ & $\begin{array}{l}\% \text { Difference with } \\
\text { Strain Rate } 10^{8} \mathrm{~s}^{-1}\end{array}$ & $\begin{array}{l}\text { Young's } \\
\text { Modulus } \\
\text { (GPa) }\end{array}$ & $\begin{array}{l}\% \text { Difference with } \\
\text { Strain Rate } 10^{8} \mathrm{~s}^{-1}\end{array}$ \\
\hline Pristine & 70.346 & 72.711 & 3.36 & 81.501 & 15.85 \\
\hline $\begin{array}{l}2 \% \\
\text { Vacancy } \\
\text { Defect }\end{array}$ & 61.727 & 64.635 & 4.71 & 74.501 & 20.69 \\
\hline $\begin{array}{l}4 \% \\
\text { Vacancy } \\
\text { Defect }\end{array}$ & 48.835 & 49.948 & 2.28 & 55.135 & 12.90 \\
\hline $\begin{array}{l}6 \% \\
\text { Vacancy } \\
\text { Defect }\end{array}$ & 39.57 & 41.569 & 5.05 & 49.248 & 24.45 \\
\hline
\end{tabular}

\subsubsection{Yield strength for various strain rates with vacancy defects}

The yield strength for $(4,4)$ vacancy defective SWCNT/PP nanocomposites with different strain rates has been plotted in Fig. 17. It could be seen that the yield strength varied on changing the strain rate. Table 8 shows the comparison of yield strength with strain rate. It was observed that with the increase in strain rate, the yield strength of the SWCNT/PP nanocomposites enhanced. It was also seen all over this study that when the percent vacancy defects increase, the value of yield strength falls. The carbon atom of SWCNT was reduced, which resulted in this decrease. During the formation of vacancy defect, the carbon atom gets deleted from SWCNT. The strain rate of $10^{10} \mathrm{~s}^{-1}$ showed maximum yield strength. 
Table 8

Comparison of yield strength for vacancy defective SWCNT/PP nanocomposites with various strain rates.

\begin{tabular}{|c|c|c|c|c|c|}
\hline \multirow{2}{*}{$\begin{array}{l}\text { Types of } \\
\text { SWCNT }\end{array}$} & \multirow{2}{*}{$\begin{array}{l}\text { Strain Rate } \\
10^{8} \mathrm{~s}^{-1} \\
\text { Yield } \\
\text { Strength } \\
(\mathrm{GPa})\end{array}$} & \multicolumn{2}{|c|}{ Strain Rate $10^{9} \mathrm{~s}^{-1}$} & \multicolumn{2}{|c|}{ Strain Rate $10^{10} \mathrm{~s}^{-1}$} \\
\hline & & $\begin{array}{l}\text { Yield } \\
\text { Strength } \\
\text { (GPa) }\end{array}$ & $\begin{array}{l}\% \text { Difference with } \\
\text { Strain Rate } 10^{8} \mathrm{~s}^{-1}\end{array}$ & $\begin{array}{l}\text { Yield } \\
\text { Strength } \\
(\mathrm{GPa})\end{array}$ & $\begin{array}{l}\% \text { Difference with } \\
\text { Strain Rate } 10^{8} \mathrm{~s}^{-1}\end{array}$ \\
\hline Pristine & 1.4069 & 1.4542 & 3.36 & 1.793 & 27.44 \\
\hline $\begin{array}{l}2 \% \\
\text { Vacancy } \\
\text { Defect }\end{array}$ & 1.3579 & 1.4219 & 4.71 & 1.6486 & 21.40 \\
\hline $\begin{array}{l}4 \% \\
\text { Vacancy } \\
\text { Defect }\end{array}$ & 0.9766 & 0.9998 & 2.37 & 1.1027 & 12.91 \\
\hline $\begin{array}{l}6 \% \\
\text { Vacancy } \\
\text { Defect }\end{array}$ & 0.7914 & 0.8314 & 5.05 & 0.9849 & 24.45 \\
\hline
\end{tabular}

\subsubsection{Compressive strength for various strain rates with vacancy defects}

The variation of the compressive strength has been shown in Fig. 18 for $(4,4)$ vacancy defective SWCNT/PP nanocomposites with a variety of strain rates. Compressive strength was also impacted by different strain rates. The comparison of compressive strength with various strain rates has been listed in Table 9. The compressive strength of the SWCNT-PP nanocomposites was enhanced with an increase in the strain rate. It was found that the value of compressive strength decreases continuously with the increase in the percent vacancy defects. This reduction occurred because the carbon atom of SWCNT was decreased. The carbon atom in SWCNT is removed during the development of a vacancy defect. With a strain rate of $10^{10} \mathrm{~s}^{-1}$, the maximum compressive strength was recorded. 
Table 9

Comparison of compressive strength for vacancy defective SWCNT/PP nanocomposites with various strain rates.

\begin{tabular}{|llllll|}
\hline $\begin{array}{l}\text { Types of } \\
\text { SWCNT }\end{array}$ & $\begin{array}{l}\text { Strain Rate } \\
10^{8} \mathrm{~s}^{-1}\end{array}$ & \multicolumn{2}{l}{ Strain Rate $10^{9} \mathrm{~s}^{-1}$} & \multicolumn{2}{l|}{ Strain Rate $10^{10} \mathrm{~s}^{-1}$} \\
\cline { 2 - 6 } & $\begin{array}{l}\text { Compressive } \\
\text { Strength } \\
\text { (GPa) }\end{array}$ & $\begin{array}{l}\text { Compressive } \\
\text { Strength } \\
\text { (GPa) }\end{array}$ & $\begin{array}{l}\text { Sifference with } \\
\text { Strain Rate } 10^{8} \mathrm{~s}^{-1}\end{array}$ & $\begin{array}{l}\text { Compressive } \\
\text { Strength } \\
\text { (GPa) }\end{array}$ & $\begin{array}{l}\text { \% Difference } \\
\text { with Strain Rate } \\
10^{8} \mathrm{~s}^{-1}\end{array}$ \\
\hline Pristine & 2.5597 & 2.6646 & 4.09 & 3.0258 & 18.20 \\
\hline $\begin{array}{l}2 \% \\
\begin{array}{l}\text { Vacancy } \\
\text { Defect }\end{array}\end{array}$ & 2.3473 & 2.3806 & 1.42 & 2.8781 & 22.61 \\
\hline $\begin{array}{l}4 \% \\
\begin{array}{l}\text { Vacancy } \\
\text { Defect }\end{array}\end{array}$ & 1.9468 & 1.9896 & 2.20 & 2.4579 & 26.25 \\
\hline $\begin{array}{l}\text { 6\% } \\
\text { Vacancy } \\
\text { Defect }\end{array}$ & 1.2325 & 1.3447 & 9.10 & & \\
\hline
\end{tabular}

\subsection{Comparative study}

The results of this study have been compared with a previous study by Huang and Rodrigue [1] where the effect of strain rate on pristine SWCNT/PP nanocomposites has been studied. In [1], the opted strain rates were $0.05,0.5$, and $5 \mathrm{~min}^{-1}$. The compressive stress values have been compared in Table 10 . It could be observed that due to the very high strain rate the difference in the values of compressive stress was also high. From this comparison, it could be inferred that the value of stress gets enhanced with a higher order of strain rate.

Table 10

Comparison with the previous study.

\begin{tabular}{|lllll|}
\hline \multicolumn{2}{|l}{ Huang and Rodrigue (2014) } & \multicolumn{2}{l}{ This Study } & \multirow{2}{*}{ \% Difference } \\
\cline { 1 - 4 } Strain Rate & Compressive Stress & Strain Rate & Compressive Stress & \\
\cline { 1 - 4 } $0.05 \mathrm{~min}^{-1}$ & $56.266 \mathrm{MPa}$ & $10^{8} \mathrm{~s}^{-1}$ & $2559 \mathrm{MPa}$ & 97.80 \\
\hline $0.5 \mathrm{~min}^{-1}$ & $60.006 \mathrm{MPa}$ & $10^{9} \mathrm{~s}^{-1}$ & $2664 \mathrm{MPa}$ & 97.74 \\
\hline $5 \mathrm{~min}^{-1}$ & $62.098 \mathrm{MPa}$ & $10^{10} \mathrm{~s}^{-1}$ & $3025 \mathrm{MPa}$ & 97.95 \\
\hline
\end{tabular}

\section{Conclusions}

SWCNTs have improved the properties of polymers and nanocomposites materials. Nanocomposite made of SWCNTs can offer a novel material that is highly robust and incredibly light in weight. It is very 
costly and difficult to fabricate the SWCNT composites experimentally. Analytical models are not easy to build. As a result, modeling and simulations on the computer might be used to solve this problem. The major outputs of this study have been mentioned below.

1. In this study, the effects of strain rate on the SWCNT reinforced PP nanocomposites were investigated by using MD. It was found that Young's modulus of the SWCNT-PP nanocomposites improved on increasing the strain rate.

2. It was observed that yield strength get affected by the strain rate.

3. It was found that the compressive strength of SWCNT-PP nanocomposites improved by increasing the strain rate on the nanocomposites As the strain rate increases, the yield strength of the SWCNTPP nanocomposites also improved..

4. The effect of defects was also investigated in this study. Percent defect was varied. It was observed that with the increase in percent defect the mechanical properties of the SWCNT-PP composite were decreased.

5. In this investigation, the two types of defects were employed. The effects of both SW and vacancy defects were examined. It was observed that the vacancy defect affected the SWCNT-PP nanocomposites more than the SW defect.

A wide range of work can be done on SWCNT reinforced polymer composites by using MD simulation. In the continuation of the present work, the effect of strain rate on SWCNT-PP nanocomposites having different chiralities can be studied. The present work can be continued to investigate the effect of strain rate at different stages of SWCNT pullout. In a further study, the impact of varying strain rates can be simulated on SWCNT-PP nanocomposites having different temperature ranges. The effect of strain rate can be investigated on SWCNT-PP nanocomposites reinforced with CNTs having different aspect ratios. MD simulation can be performed to see the effect of strain rate on SWCNT-PP nanocomposites having different functional groups.

\section{Declarations}

\section{Acknowledgment}

The authors are highly thankful to the Department of Mechanical Engineering of IIT Ropar and also to the Department of Mechanical Engineering of NIT Jalandhar for providing the facilities for conducting this research.

Funding: The authors state that no funding of any type was received for this work.

Conflict of interest: The authors declare that they have no known competing financial interests or personal relationships that could have appeared to influence the work reported in this paper.

Availability of data and material: The manuscript has no associated data. All the data has been provided in the manuscript. 
Code availability: Not applicable

\section{Authors contributions:}

Author 1: Brijesh Mishra

- Wrote original draft

- Performed investigation

- Performed formal analysis

Author 2: Sumit Sharma

- Conceptualized the work

- Methodology

- Performed review and editing

Ethics Approval: The authors state that this work is original. The authors also state that this manuscript has not been submitted nor published in any other journal.

Consent to participate: Not applicable

Consent for publication: The authors give their consent for publication in this journal.

\section{References}

1. Huang J., and Rodrigue D. (2014) "The effect of carbon nanotube orientation and content on the mechanical properties of polypropylene-based composites." Materials and Design, Vol. 55, pp. 653663.

2. Parvaneh V., and Shariati M. (2016) "Effect of defects and loading on prediction of Young's modulus of SWCNTs," Acta Mechanica, Vol. 216(1-4), pp. 281-289.

3. Jacob G.C., Starbuck J.M., Fellers J.F., Simunovic S., Boeman RG. (2004) "Strain rate effects on the mechanical properties of polymer composite materials." Journal of Applied Polymer Science, Vol. 94, pp 296-301.

4. Saxena K.K., and Lal A. (2012) "Comparative molecular dynamics simulation study of mechanical properties of carbon nanotubes with number of Stone Wales and vacancy defects." Procedia Engineering, Vol. 38, pp 2347-2355.

5. Yang S., Yu S., Cho M. (2012) "Influence of Thrower-Stone-Wales defects on the interfacial properties of carbon nanotube/polypropylene composites by a molecular dynamics approach." Carbon, Vol. 55, pp 133-143.

6. Sharma S., Chandra R., Kumar P., Kumar N. (2014) "Effect of Stone-Wales and vacancy defects on elastic moduli of carbon nanotubes and their composites using molecular dynamics 
simulation." Computational Materials Science, Vol. 86, pp 1-8.

7. Li J., Zhao J., Ren P., Dong H., Meng B., Hu S. (2019) "Effects of temperature, strain rate and molecule length on the deformation of graphene/polyethylene composites: A molecular dynamics simulation." Chemical Physics Letters, Vol. 726, pp 39-45.

8. Zhang M., Jiang B., Chen C., Drummer D., Zhai Z. (2019) "The effect of temperature and strain rate on the interfacial behavior of glass fiber reinforced polypropylene composites: A molecular dynamics study." MDPI Journal, Polymers, Vol. 11, p. 1766.

9. Khan, F.S.A., Mubarak, N.M., Khalid, M. et al. Functionalized multi-walled carbon nanotubes and hydroxyapatite nanorods reinforced with polypropylene for biomedical application. Sci Rep 11, 843 (2021). https://doi.org/10.1038/s41598-020-80767-3.

10. Schossig, M., Bieroegel, C., Grellmann, W., Bardenheier, R., Mecklenburg, T. (2006) Effect of strain rate on mechanical properties of reinforced polyolefins. In: Gdoutos E.E. (eds) Fracture of Nano and Engineering Materials and Structures. Springer, Dordrecht. https://doi.org/10.1007/1-4020-49722_251.

11. Fitoussi, J., Bocquet, M., Meraghni, F. (2013) “Effect of the matrix behavior on the damage of ethylene-propylene glass fiber reinforced composite subjected to high strain rate tension." Composites Part B: Engineering, Vol. 45, pp. 1181-1191.

12. Notta-Cuvier, D., Nciri M., Lauro, F., Delille, R., Chaari, F., Robache, F., Haugou, G., Maalej, Y. (2016) "Coupled influence of strain rate and heterogeneous fibre orientation on the mechanical behaviour of short-glass-fibre reinforced polypropylene." Mechanics of Materials, Vol. 100, pp. 186-197.

13. Cui, J., Wang, S., Wang, S., Li, G., Wang, P., and Liang, C. (2019) "The effects of strain rates on mechanical properties and failurebehavior of long glass fiber reinforced thermoplastic composites." Polymers (Basel), Vol. 11(12), pp. 1-18.

14. Kim, D.H., Kang, S.Y., Kim, H.J., Kim, H.S. (2019) "Strain rate-dependent mechanical behavior of glass fiber-reinforced polypropylene composites and its effect on the performance of automotive bumper beam structure." Composites Part B Engineering, Vol. 166, pp. 483-496.

15. Zhang, M., Jiang, B., Chen, C., Drummer, D., and Zhai, Z. (2019) "The effect of temperature and strain rate on the interfacial behavior of glass fiber reinforced polypropylene composites: A molecular dynamics study." MDPI Journal, Polymers, Vol. 11, pp. 1-18.

\section{Figures}



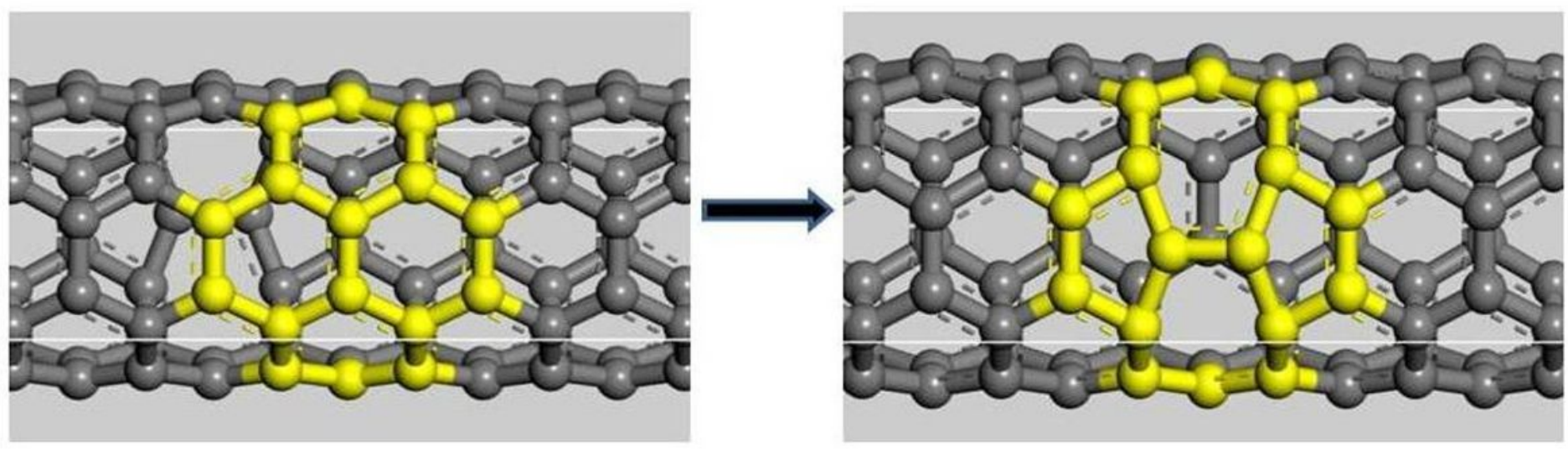

\section{Figure 1}

Stone-Wales defect formation.
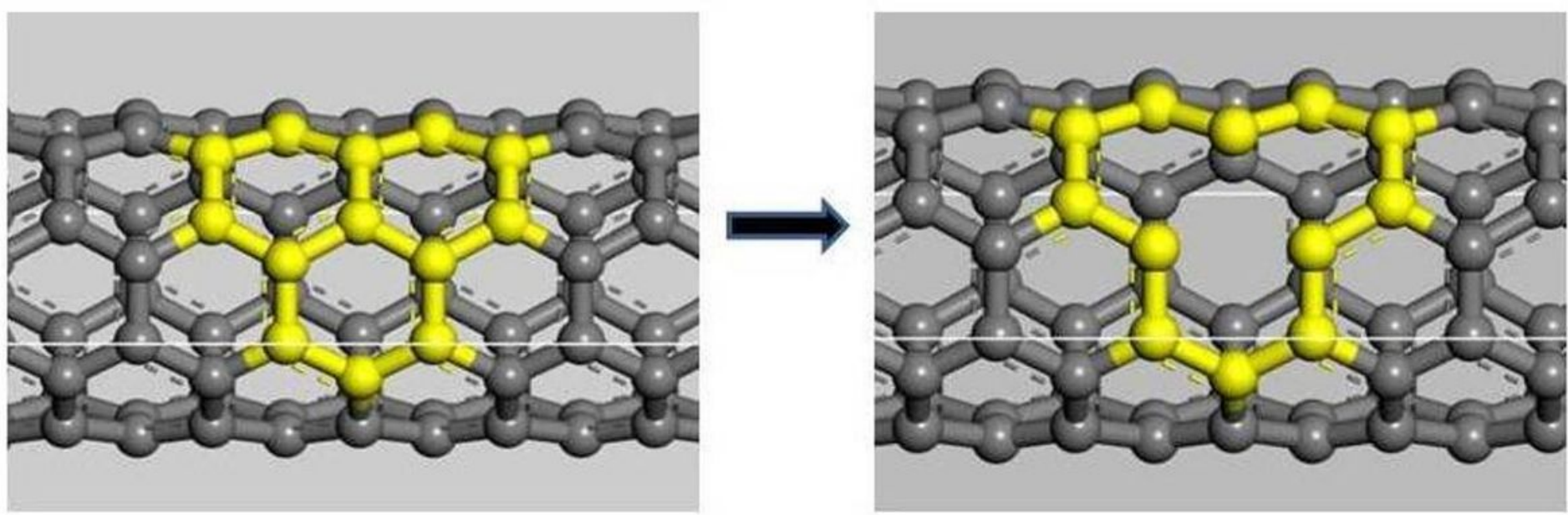

Figure 2

Vacancy defect formation. 


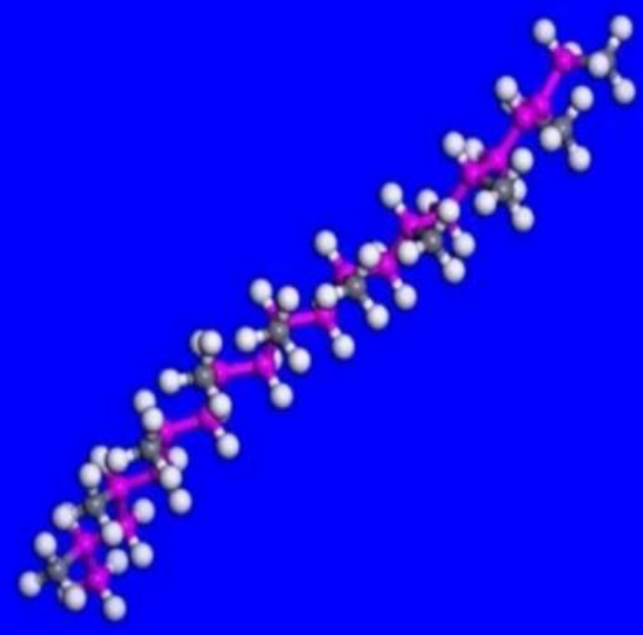

Figure 3

PP with 18 numbers monomers.

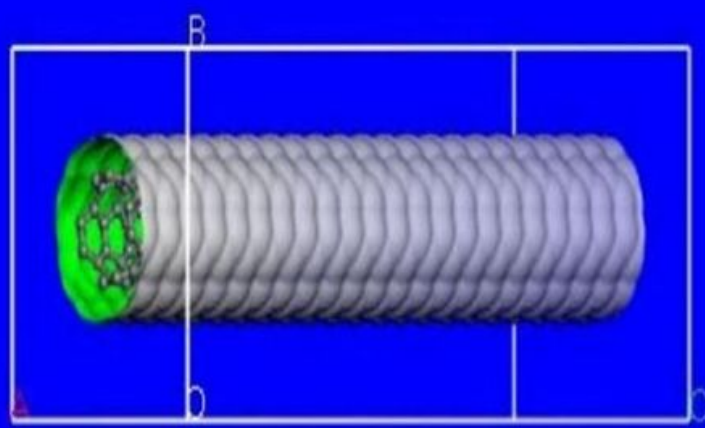


Figure 4

An iso-surface around SWCNT.

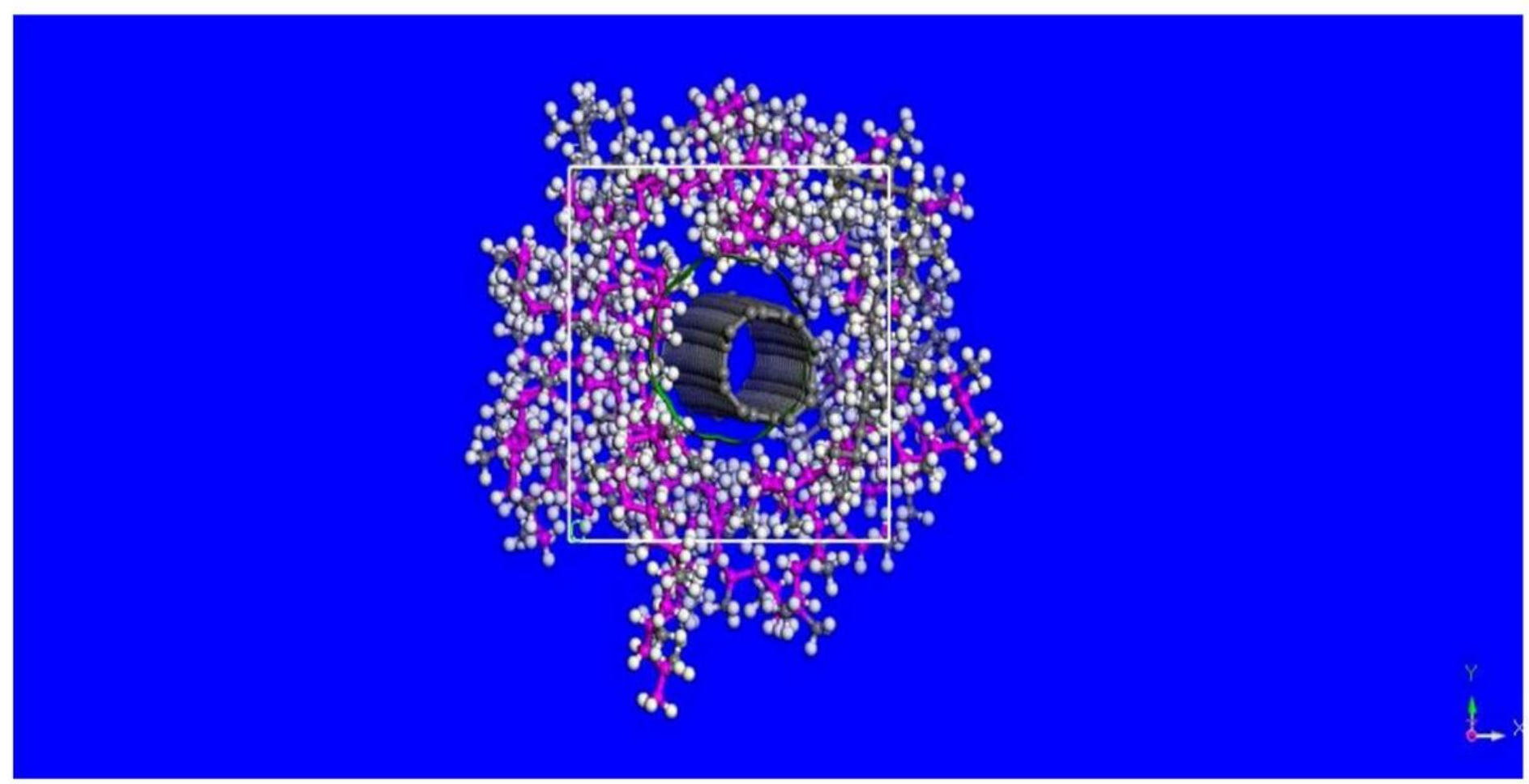

Figure 5

Polypropylene packed in the cell with SWCNT having 2008 atoms. 


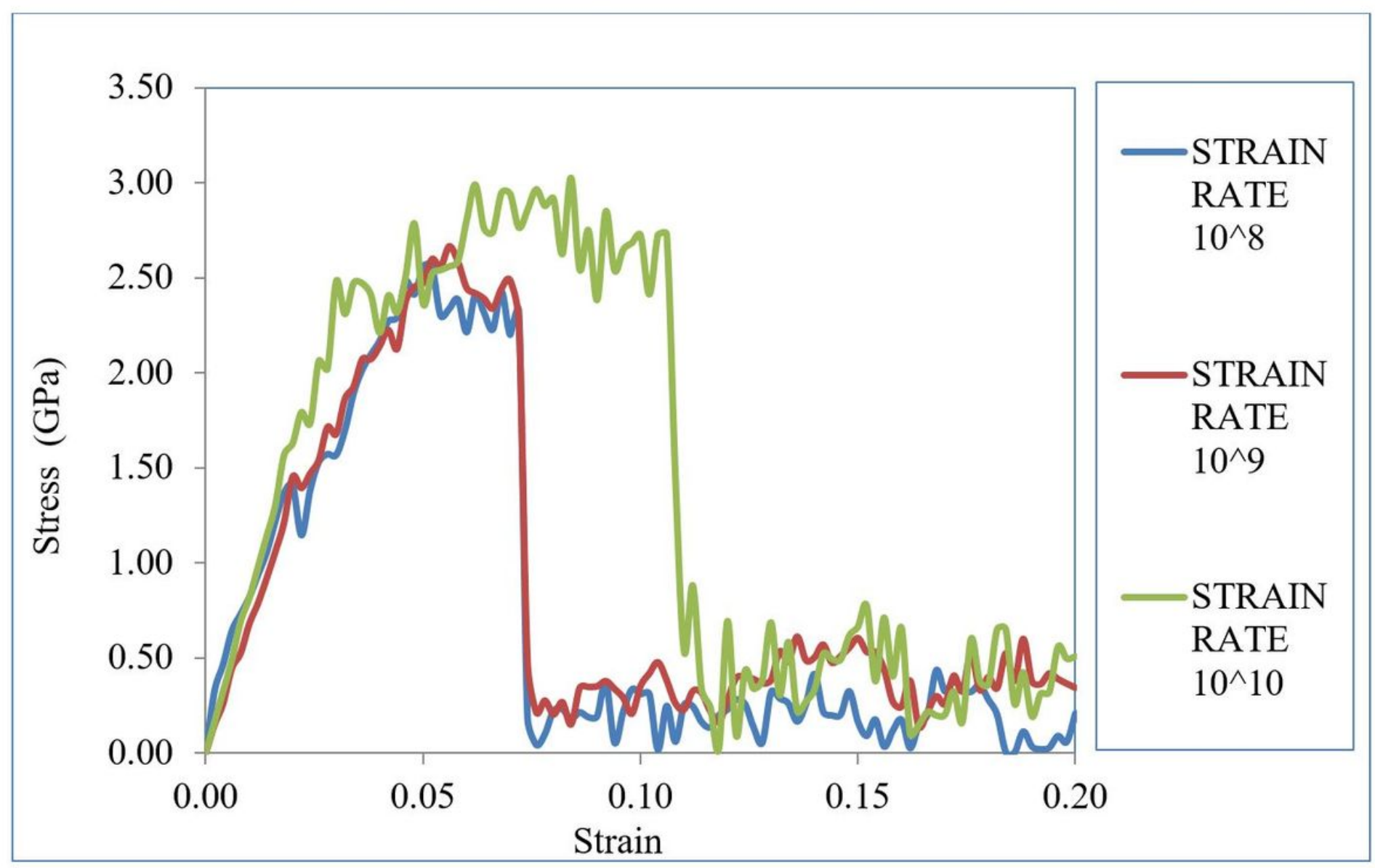

\section{Figure 6}

Stress-strain curve under compression for $(4,4)$ pristine SWCNT/PP nanocomposites having 0.65 volume fraction. 


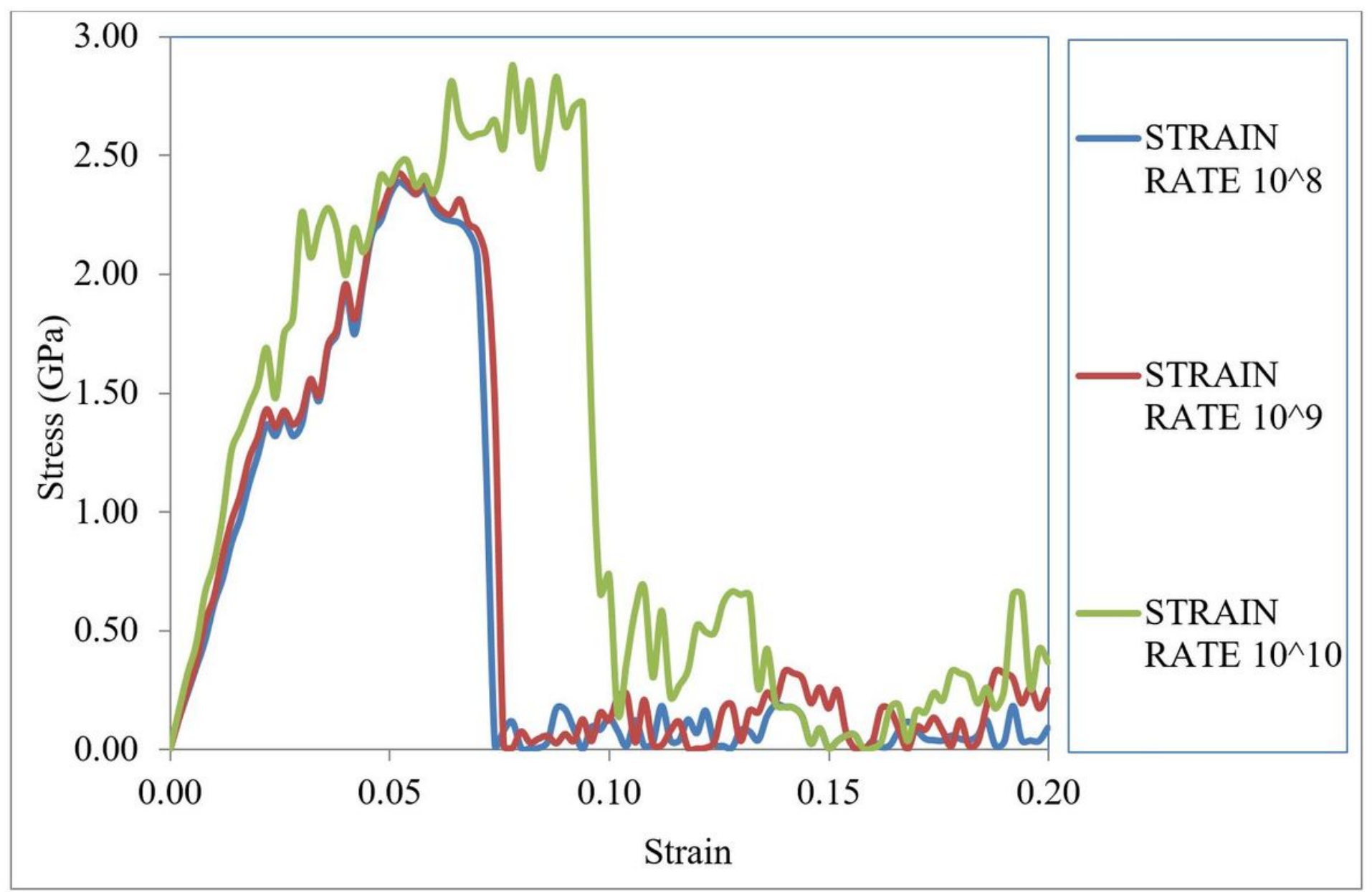

Figure 7

Stress-strain curve under compression for $(4,4) 2 \%$ SW defective SWCNT/PP nanocomposites having 0.65 volume fraction. 


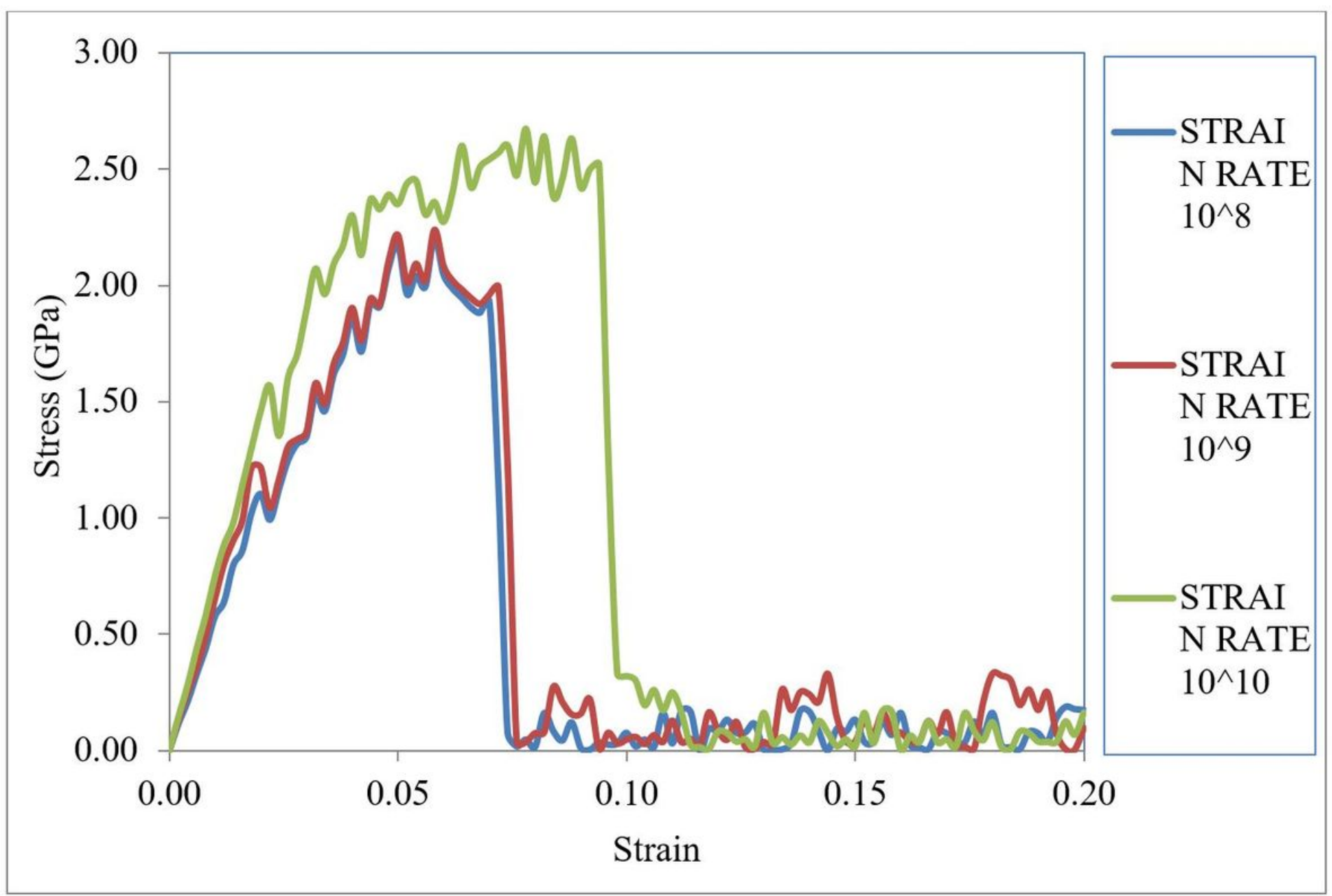

Figure 8

Stress-strain curve under compression for $(4,4) 4 \%$ SW defective SWCNT/PP nanocomposites having 0.65 volume fraction. 


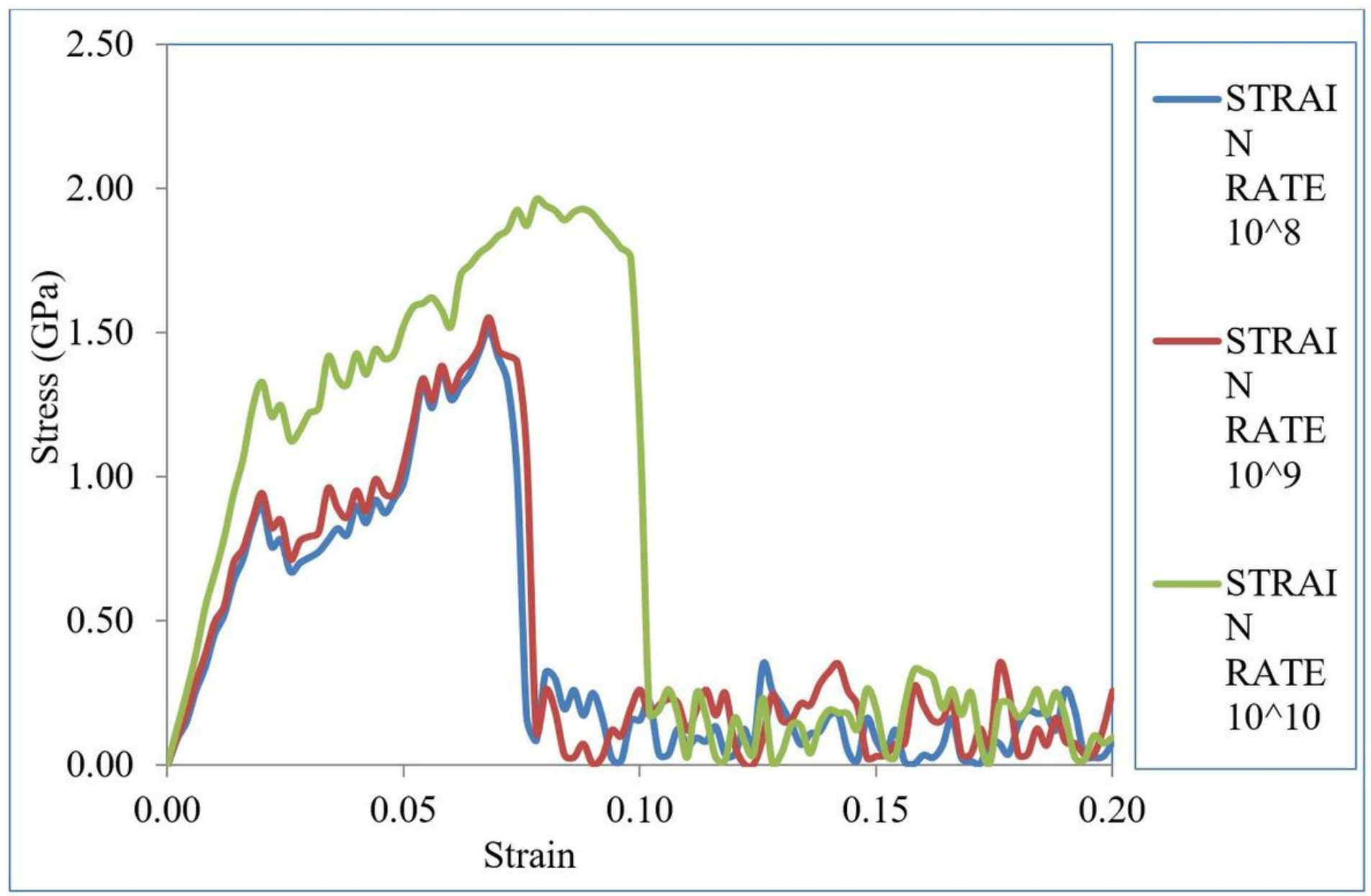

Figure 9

Stress-strain curve under compression for $(4,4) 6 \%$ SW defective SWCNT/PP nanocomposite having 0.65 volume fraction. 


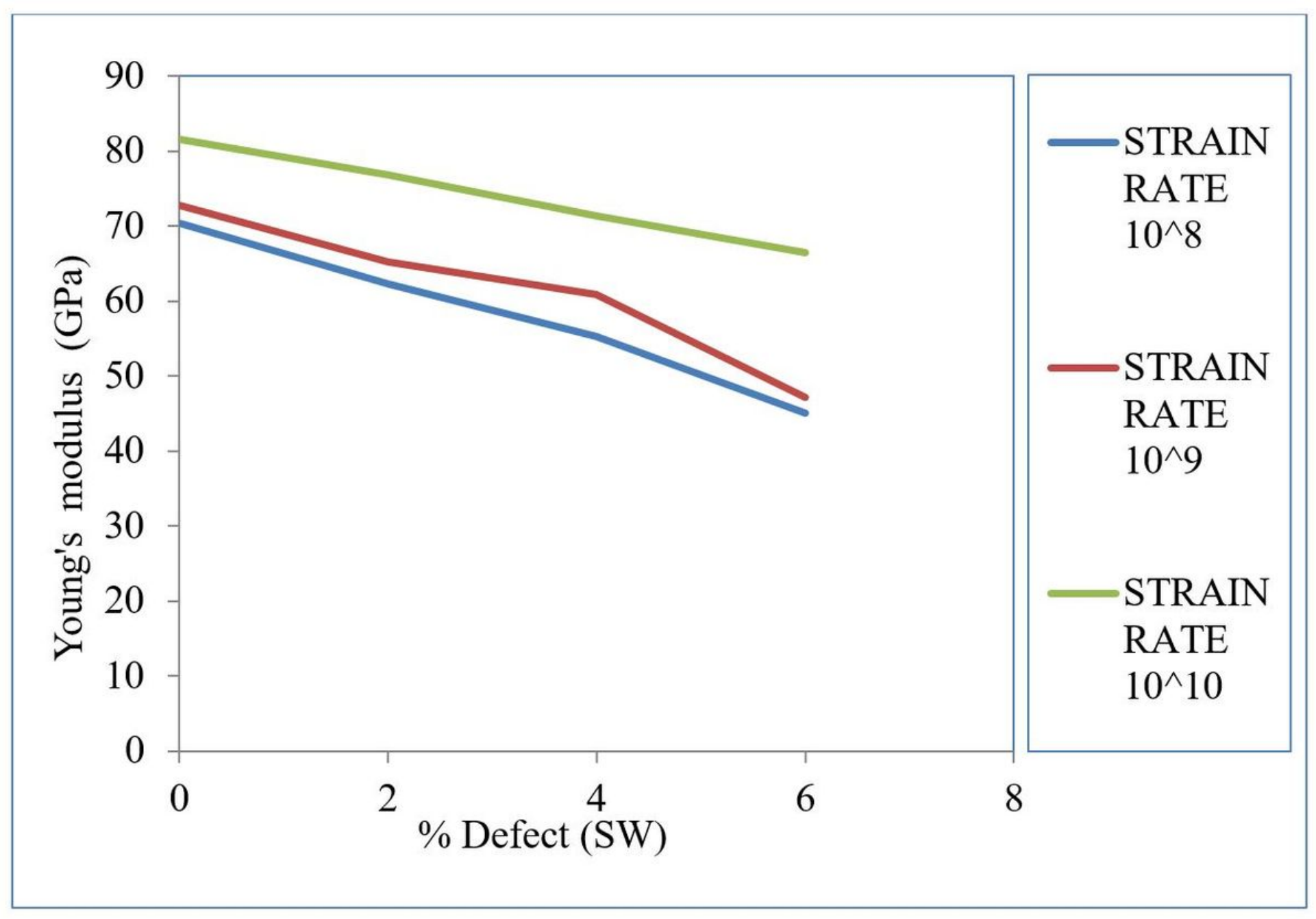

Figure 10

Variation of Young's modulus for various strain rates for $(4,4)$ SW defective SWCNT/PP nanocomposites. 


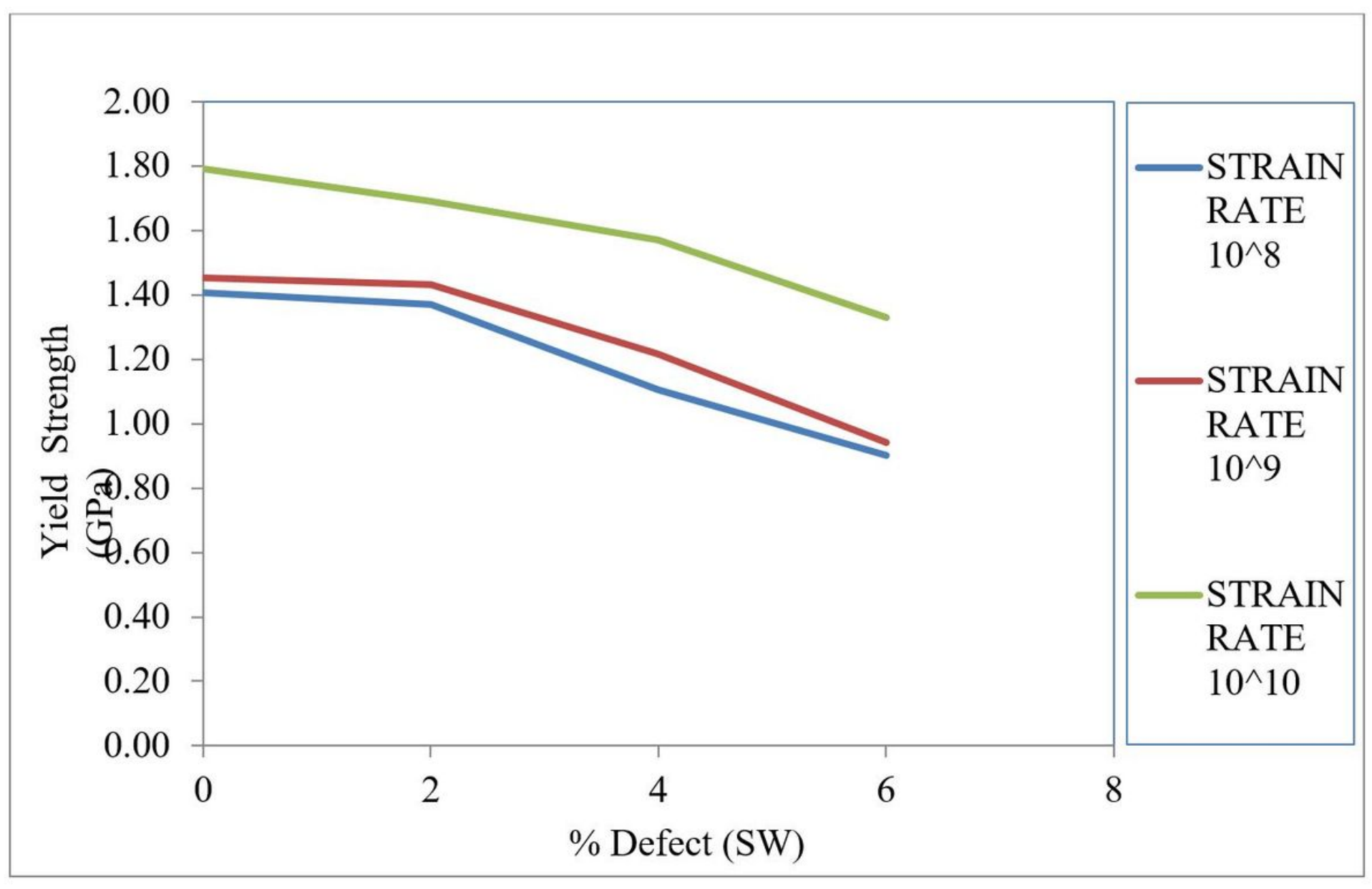

Figure 11

Variation of the yield strength for various strain rates for $(4,4)$ SW defective SWCNT/PP nanocomposites. 


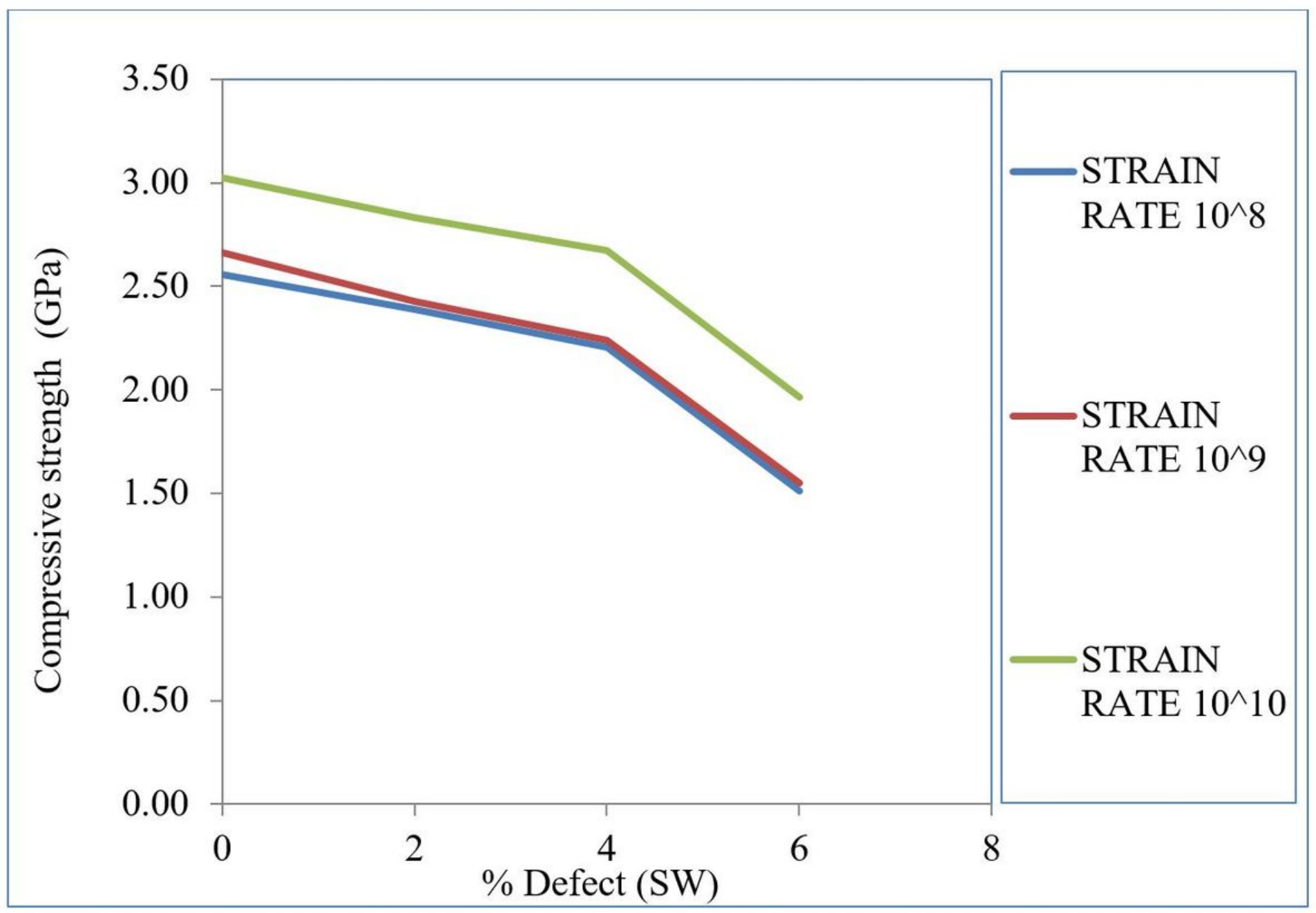

Figure 12

Variation of the compressive strength for various strain rates for $(4,4)$ SW defective SWCNT/PP nanocomposites. 


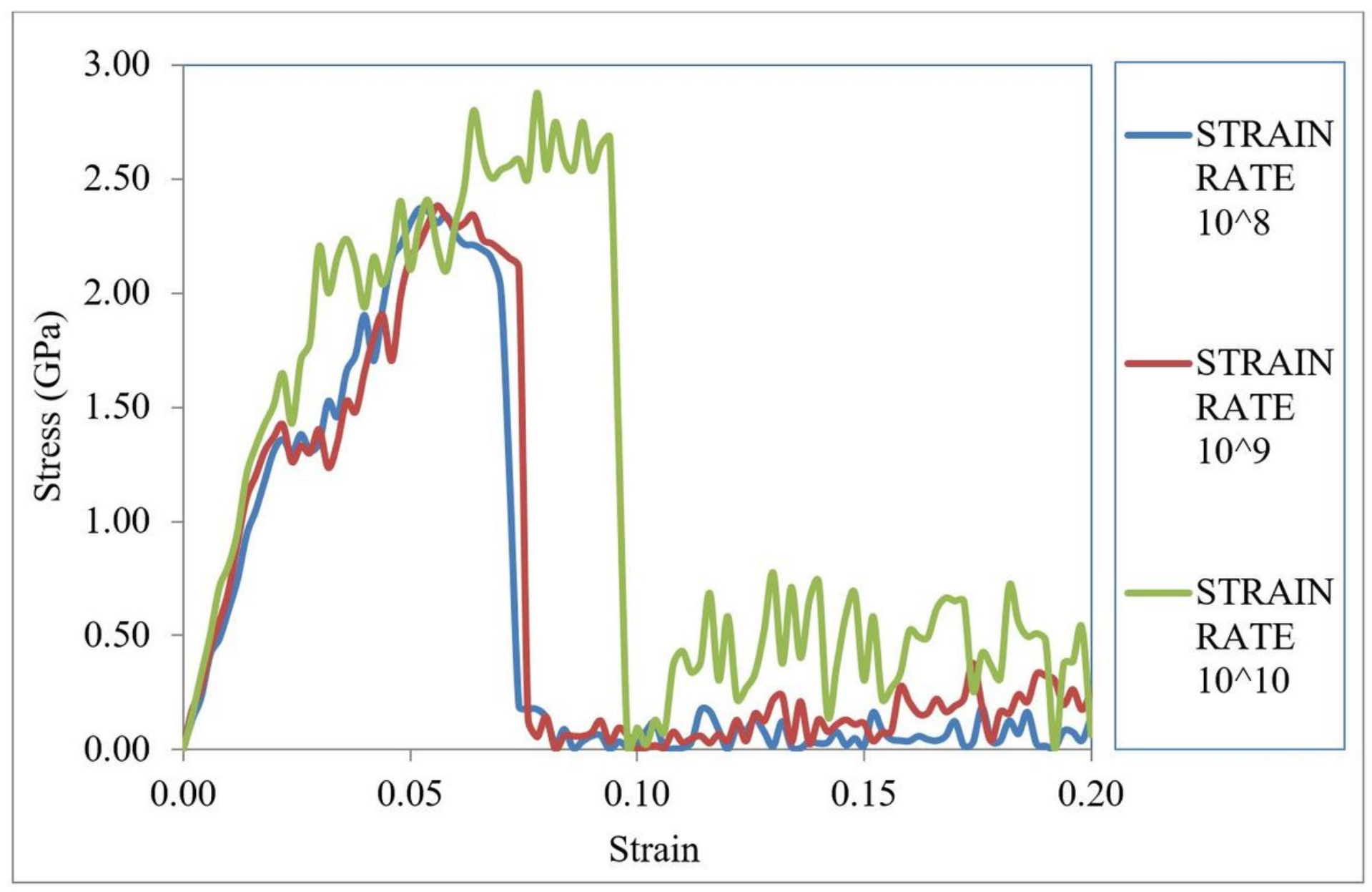

Figure 13

Stress-strain curve under compression for $(4,4) 2 \%$ vacancy defective SWCNT/PP nanocomposites having 0.65 volume fraction. 


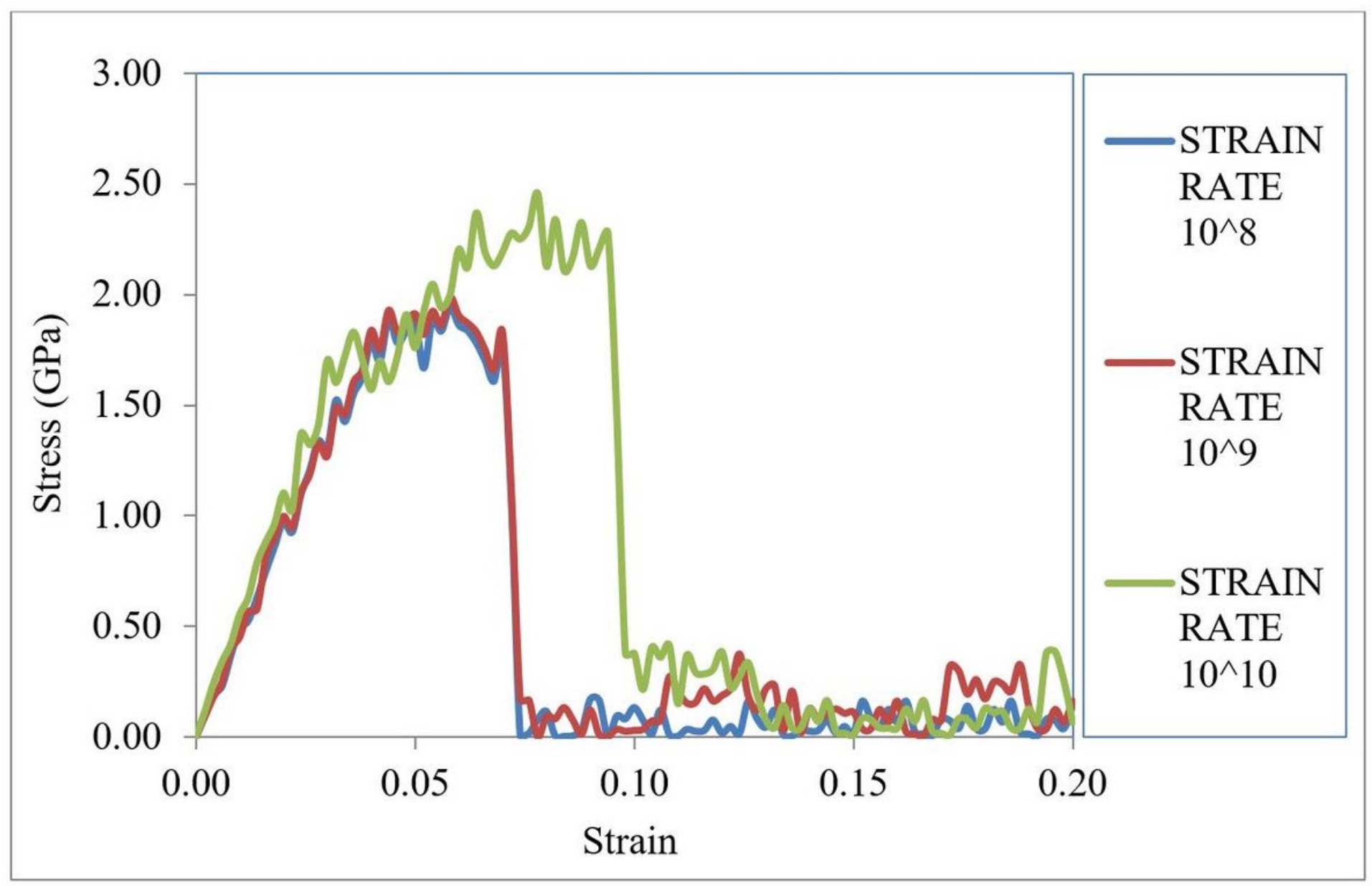

Figure 14

Stress-strain curve under compression for $(4,4) 4 \%$ vacancy defective SWCNT/PP nanocomposites having 0.65 volume fraction. 


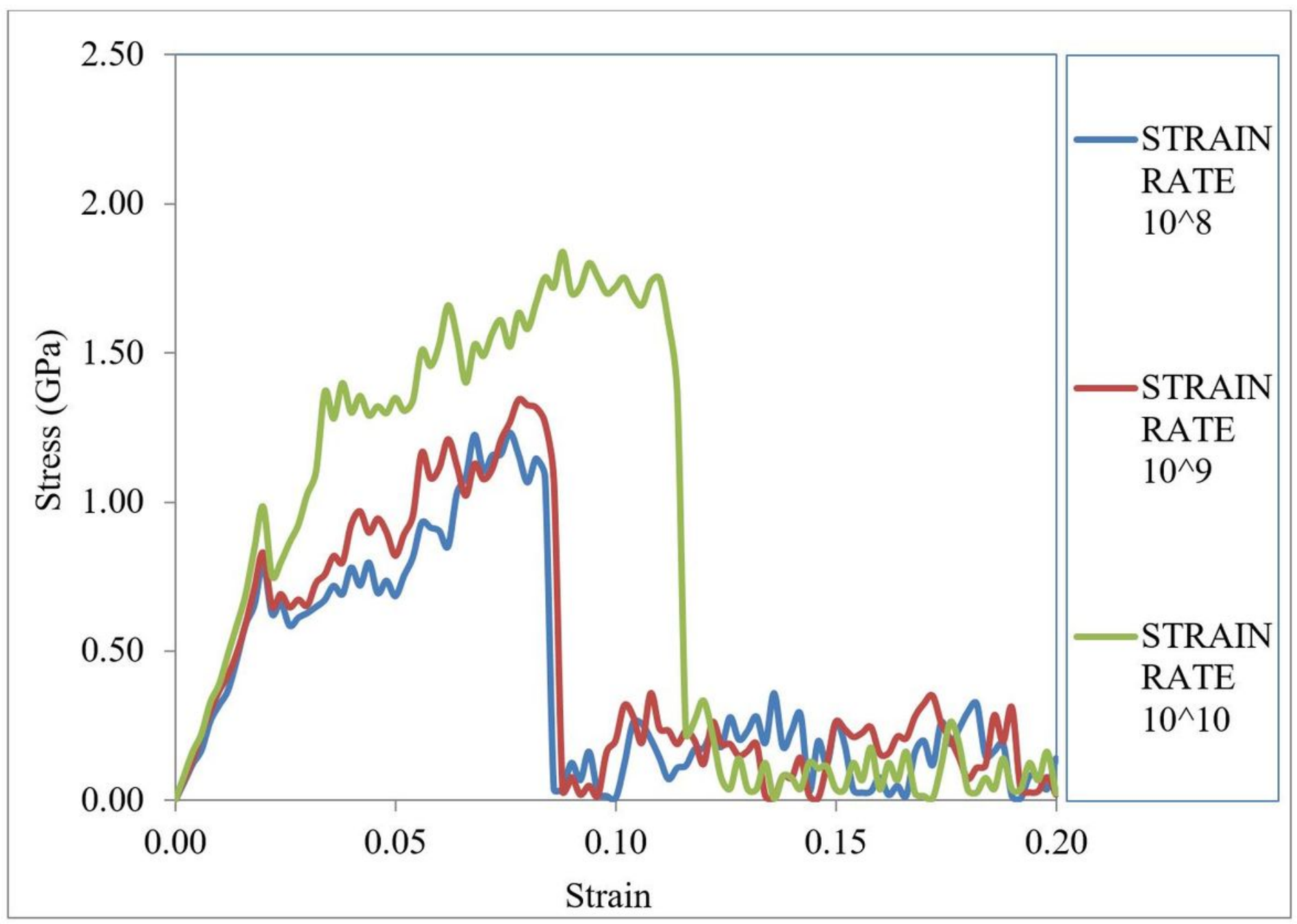

Figure 15

Stress-strain curve under compression for $(4,4) 6 \%$ vacancy defective SWCNT/PP nanocomposites having 0.65 volume fraction. 


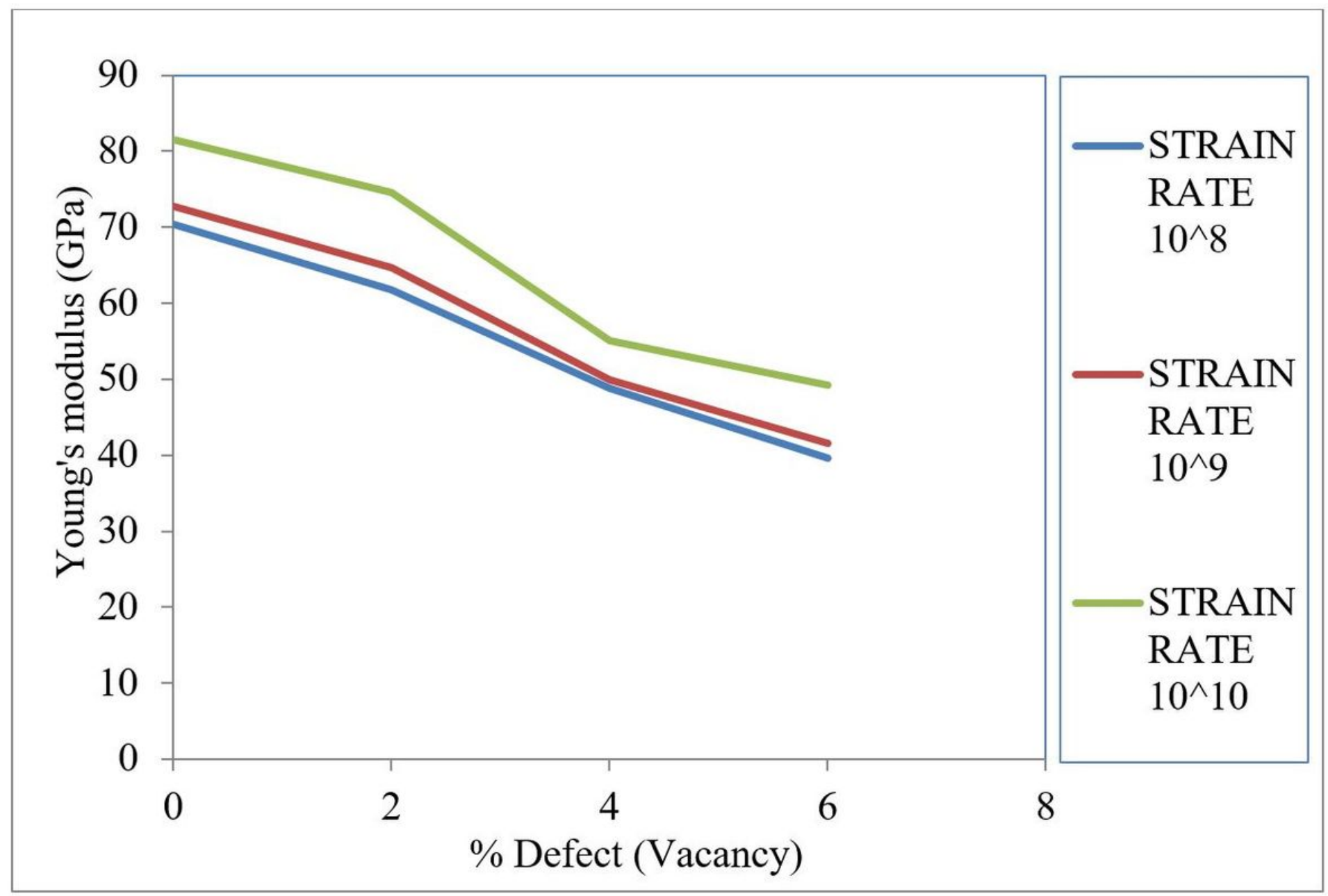

Figure 16

Variation of the Young's modulus for various strain rates for $(4,4)$ vacancy defective SWCNT/PP nanocomposites. 


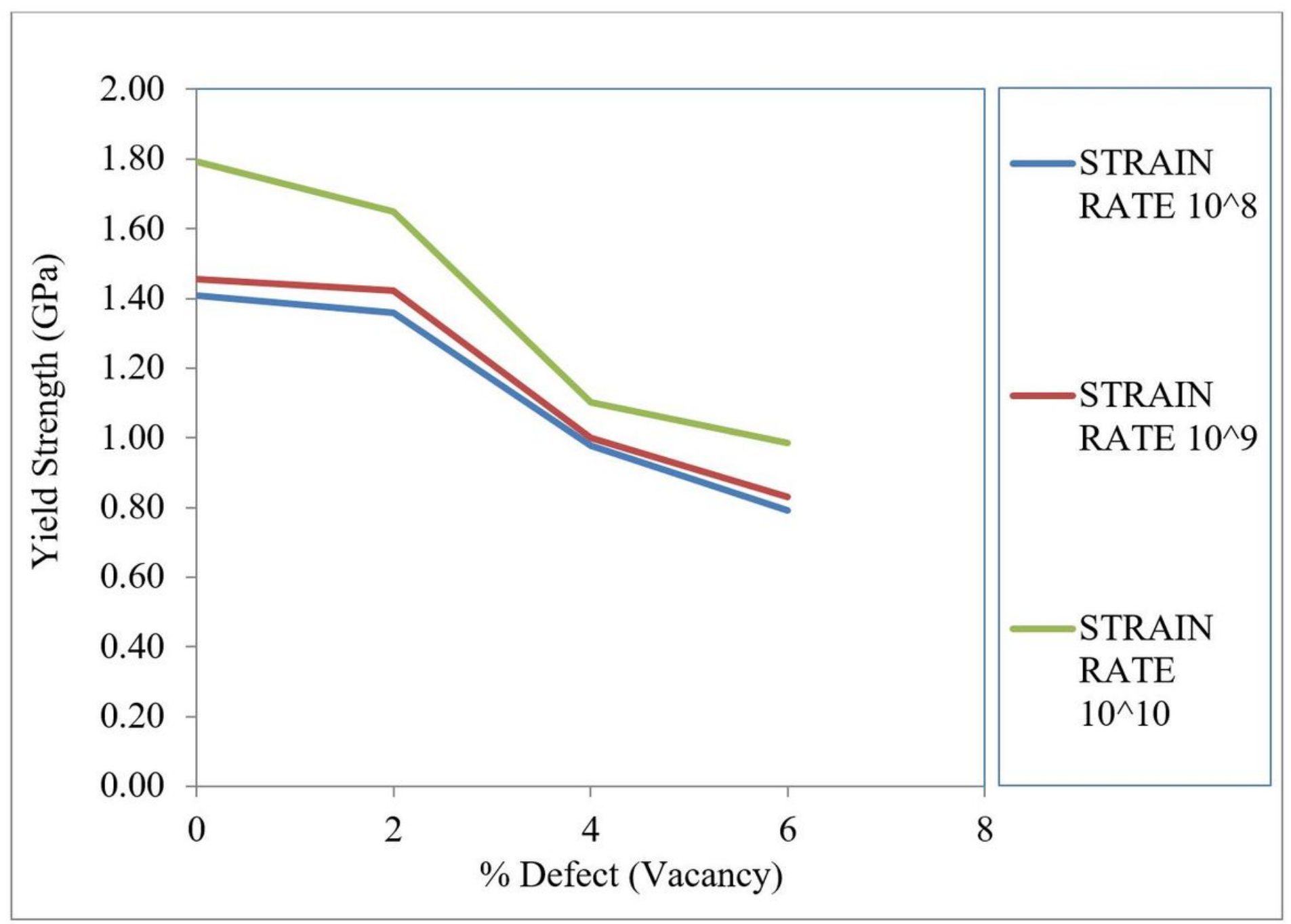

Figure 17

Variation of the yield strength for various strain rates for $(4,4)$ vacancy defective SWCNT/PP nanocomposites. 


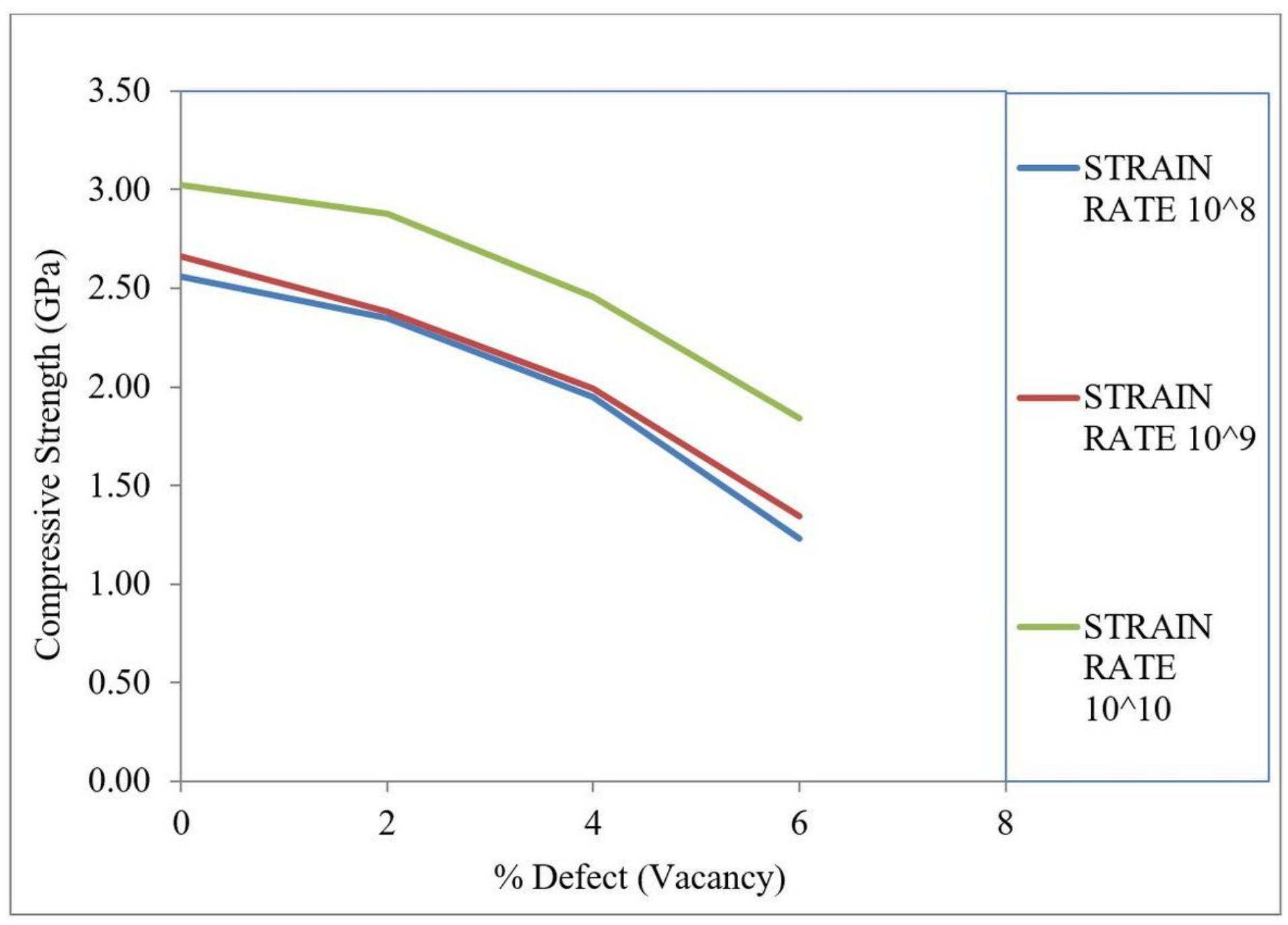

\section{Figure 18}

Variation of the compressive strength for various strain rates for $(4,4)$ vacancy defective SWCNT/PP nanocomposites.

\section{Supplementary Files}

This is a list of supplementary files associated with this preprint. Click to download.

- Graphicalabstract.docx 